\title{
EL GÉNERO DEYEUXIA (POACEAE, AGROSTIDEAE) EN SITIOS ARQUEOLÓGICOS DE LA PUNA MERIDIONAL ARGENTINA, PROVINCIA DE CATAMARCA
}

\author{
THE GENUS DEYEUXIA (POACEAE, AGROSTIDEAE) IN ARCHAEOLOGICAL \\ SITES OF THE SOUTHERN ARGENTINA PUNA, PROVINCE OF CATAMARCA
}

\author{
María Fernanda Rodríguez*, Zulma E. Rúgolo de Agrasar* y Carlos Aschero**
}

\begin{abstract}
Se investigó la presencia del género Deyeuxia P. Beauv. (Poaceae) durante el Holoceno medio y tardío (ca. 7410-460 a.p.) en sitios arqueológicos localizados en Antofagasta de la Sierra, Provincia de Catamarca, Puna Meridional Argentina. Un elevado número de especies pertenecientes a este género fue hallado en los sitios Quebrada Seca 3, Cueva Salamanca 1, Punta de la Peña 3, Punta de la Peña 4, Punta de la Peña 9, Punta de la Peña 11 y Peña de la Cruz 1. Se identificaron los taxones Deyeuxia eminens J. Presl var. eminens, D. eminens var. fulva (Griseb.) Rúgolo, D. deserticola Phil., D. curvula Wedd. y D. rigescens (J. Presl) Türpe mediante estudios morfológicos y anatómicos comparados con material actual, para lo cual se tomó en consideración la anatomía foliar y caulinar. A partir de la información obtenida, se discuten aspectos vinculados con las áreas de captación de recursos vegetales, la movilidad de los grupos cazadores recolectores y el uso de las especies halladas.
\end{abstract}

Palabras claves: Registro arqueobotánico, recursos vegetales, áreas de captación de recursos, Puna, Deyeuxia, Poaceae.

The presence of Deyeuxia P. Beauv. (Poaceae) genus during the Middle and Late Holocene (ca. 7410-460 B.P.) in archaeological sites situated in Antofagasta de la Sierra, Province of Catamarca, Southern Argentina Puna, is analysed. A large number of species belonging to this genus was recovered in the following sites: Quebrada Seca 3, Cueva Salamanca 1, Punta de la Peña 3, Punta de la Peña 4, Punta de la Peña 9, Punta de la Peña 11 and Peña de la Cruz 1. The taxa Deyeuxia eminens J. Presl var. eminens, D. eminens var. fulva (Griseb.) Rúgolo, D. deserticola Phil., D. curvula Wedd. and D. rigescens (J. Presl) Türpe, were identified from morphological and anatomical analysis in comparison with contemporary material; the foliar and caulinar anatomy was taken into account. Some aspects of relationships to plant resource catchment areas, hunter-gatherer groups movements and use of the recovered species are discussed based on this information.

Key words: Archaeobotanical record, plant resources, resource catchment areas, Puna, Deyeuxia,Poaceae.

En este trabajo se analizó la presencia del género Deyeuxia P. Bauv. (Poaceae) en distintos momentos del Holoceno, en sitios arqueológicos de la Puna Meridional Argentina, localizados en Antofagasta de la Sierra, Provincia de Catamarca (Figura 1). El área de estudio corresponde a la Provincia Puneña del Dominio Andino. En esta provincia la vegetación dominante es la estepa arbustiva, pero se desarrollan también las estepas herbáceas (halófila y sammófila) y la vega (Cabrera 1957; Cabrera 1976; Cabrera y Willink 1980).

Es notoria la abundancia de especies pertenecientes a este género que frecuentemente forman parte de estructuras (camadas de gramíneas y fardos funerarios) y artefactos (cordeles, sogas y nudos) en los sitios arqueológicos. Una de ellas,
Deyeuxia eminens J. Presl var. eminens, fue analizada previamente (Rodríguez 1999; Rodríguez y Rúgolo de Agrasar 1999) y las siguientes: $D$. eminens var. fulva (Griseb.) Rúgolo, D. deserticola Phil., D. curvula Wedd. y D. rigescens (J. Presl) Türpe, fueron citadas recientemente (Rodríguez 2000). Estas especies fueron recuperadas en los sitios: Quebrada Seca 3, Cueva Salamanca 1, Punta de la Peña 3, Punta de la Peña 4, Punta de la Peña 9, Punta de la Peña 11 y Peña de la Cruz 1 (Figura 1).

La identificación de las especies arqueológicas se realizó a partir de estudios morfológicos y anatómicos comparados, analizándose además órganos reproductivos en los casos en que fue posible. Para ello se tomó en consideración la anatomía foliar y caulinar.

\footnotetext{
Instituto de Botánica Darwinion, Labardén 200. C C 22, B1642HYD, San Isidro. Argentina. frodriguez@darwin.edu.ar; zrugolo@darwin.edu.ar

** Instituto de Arqueología y Museo. Facultad de Ciencias Naturales e Instituto Miguel Lillo, Universidad Nacional de Tucumán. San Martín 1545. 4000. San Miguel de Tucumán. Argentina. aschero@unt.edu.ar
} 


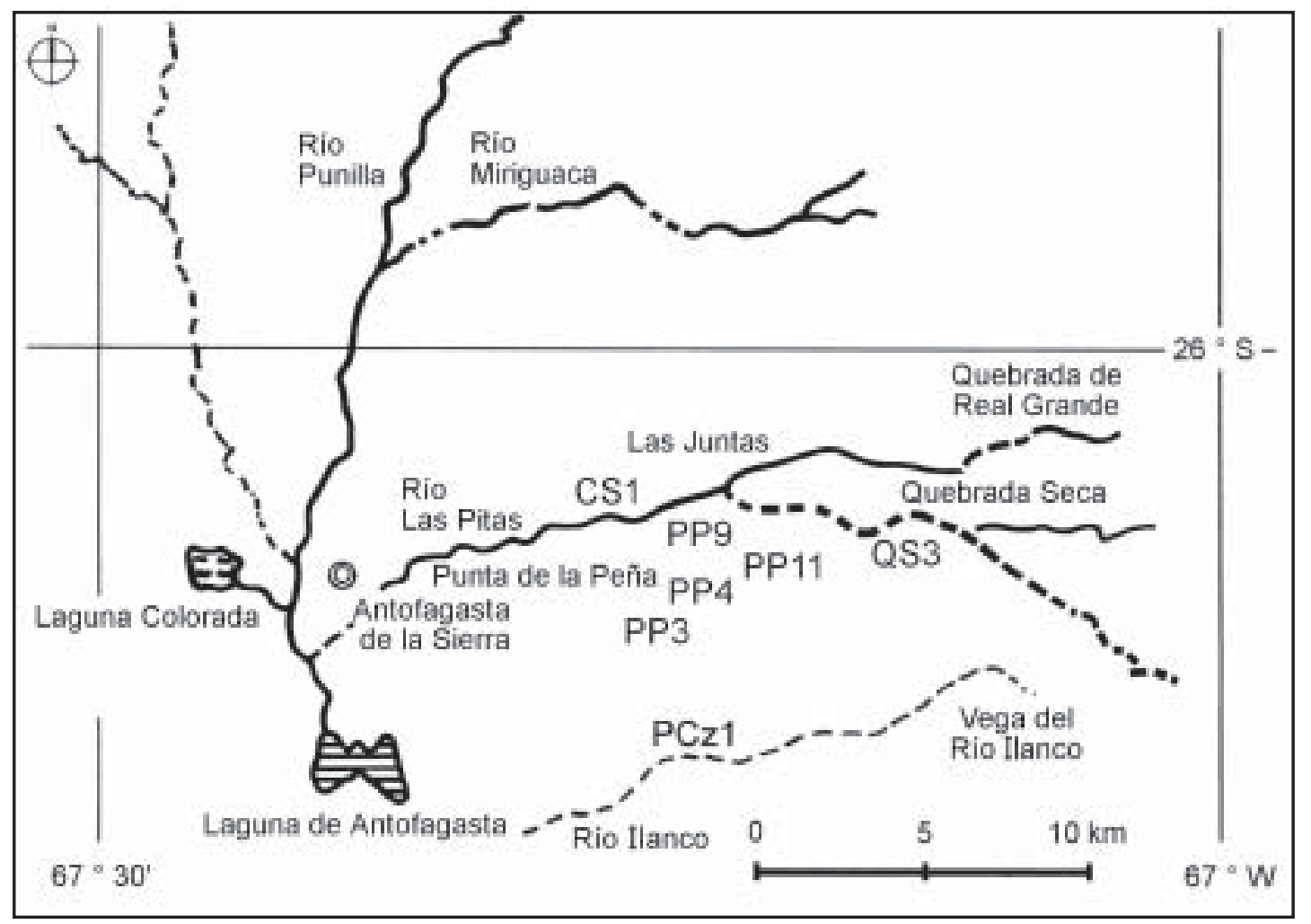

Figura 1. Localidad de Antofagasta de la Sierra, Catamarca, Argentina. Sitios arqueológicos: CS1, Cueva Salamanca 1; PP, Punta de la Peña (incluye los siguientes sitios: PP3, PP4, PP9 y PP11); PCz1, Peña de la Cruz 1; QS3, Quebrada Seca 3.

Antofagasta de la Sierra, Catamarca, Argentina, showing the following archaeological sites: CS1, Cueva Salamanca 1; PP, Punta de la Peña (including the following sites: PP3, PP4, PP9 and PP11); PCZ1, Peña de la Cruz 1; QS3, Quebrada Seca 3.

El género Deyeuxia en Sudamérica tiene un importante centro de diversificación específica en el noroeste de Argentina, norte de Chile y Bolivia, donde se registran más de 58 taxones (Rúgolo de Agrasar y Villavicencio 1998; Rúgolo de Agrasar 1999). Las especies habitan principalmente altas montañas y ocupan diversos ambientes, desde lugares secos y rocosos hasta mallines y vegas, generalmente en elevadas altitudes alcanzando hasta los $5000 \mathrm{msm}$.

Se plantearon los siguientes objetivos:

- Identificar las especies de Deyeuxia recuperadas en los sitios arqueológicos mencionados. Construir tablas que permitan determinar especies de este género a partir de los caracteres anatómicos foliares y caulinares de los taxones.

- Determinar la procedencia de las especies utilizadas, discriminando taxones locales y no lo- cales (procedentes de un radio superior a 20 $\mathrm{km})$. Inferir el grado de movilidad durante el lapso considerado (Holoceno Medio y Tardío) en el área de estudio.

- Analizar el posible uso de las especies recuperadas en los sitios arqueológicos.

\section{Descripción de los Sitios Arqueológicos}

Quebrada Seca 3 (QS3) es un abrigo situado en las proximidades del cauce de Quebrada Seca, afluente del río Las Pitas (Localidad de Quebrada Seca), en la base de uno de los farallones de ignimbritas que conforman la margen sur de dicho cauce, a una altura de $4100 \mathrm{msm}$. Está orientado hacia el NE y presenta un área de reparo de $9 \mathrm{mx}$ $5 \mathrm{~m}$. Desde el punto de vista estratigráfico, se diferenciaron cuatro unidades principales: capas $0 /$ lente 1x, 1, 2a y 2b (Rodríguez y Rúgolo de Agrasar 
1999, véase Figura 3 y Tabla 1). En la capa 2a se obtuvo un fechado de $2480 \pm 60$ a.p., LP-278, tallos de Senecio santelicis Phil. que corresponde a grupos agropastoriles del Holoceno Tardío. En la capa 2b, sedimento arenoso a areno-limoso con importantes aportes antropógenos (Aschero et al. 1991), se definieron 25 niveles de ocupación datados entre los siguientes extremos: $4510 \pm 100$ a.p., Beta-27801, Deyeuxia eminens, fardo funerario- Nivel 2b2- y $9410 \pm 120$ a.p., LP-881, carbón -Nivel 2b25- y $9790 \pm 50$ a.p., UGA-9257, carbón - Nivel 2b19- (Aschero et al. 1991; 1993 1994). Estas ocupaciones se vinculan con grupos cazadores recolectores del Holoceno Temprano y Medio.

Los siguientes sitios se encuentran en el sector del curso medio inferior del río Las Pitas. Localidad de Punta de la Peña. Cueva Salamanca 1 (CS1) está situado a una distancia de $6 \mathrm{~km}$ aproximadamente de QS3. Hasta la fecha se definieron siete capas de ocupación. La secuencia arqueológica muestra una ocupación cerámica en la superficie y en los primeros centímetros de sedimento arenoso seguida por distintos niveles acerámicos caracterizados por artefactos líticos. Estos están acompañados por vestigios faunísticos, vegetales bien conservados y estructuras de combustión (Rodríguez 1997). Las dataciones radiocarbónicas realizadas indican una antigüedad de $6250 \pm 70$ a.p., LP-931, carbón, para la capa 2 y $7410 \pm 100$ a.p., LP-615, carbón, para la capa 5, comienzos del Holoceno Medio, faltando aún los fechados de las capas 6 y 7 que probablemente correspondan al Holoceno Temprano. En ambos casos se trata de grupos cazadores recolectores.

Punta de la Peña 4 (PP4) es un abrigo rocoso de $15 \mathrm{~m}$ x $7 \mathrm{~m}$ ubicado aguas abajo de CS1 y QS3. En PP4 se distinguieron dos sectores de reparo constituidos por un alero superior y uno inferior con arte rupestre. Se diferenciaron seis capas estratigráficas: $0-a, 0-b, 1-5$. La capa 0 -a de guano suelto y 0 -b de guano compactado se registraron sólo en el fondo del alero ya que en el frente este elemento aparece suelto en el sedimento arenoso. La capa 3 es limo arcillosa, mientras que las capas 4 y 5 son areno limosas. El componente superior (capas 1 a 3) incluye dos camadas de gramíneas con abundancia de Deyeuxia. A diferencia de estas capas, la preservación del material arqueobotánico fue mala en las capas inferiores: 4 y 5 (Aschero
1999). Los fechados radiocarbónicos correspondientes al Holoceno Temprano y Tardío (Tabla 1), señalan la siguiente secuencia: $8970 \pm 60$ a.p., UGA-9255, carbón -capa 5 (5)-, $4100 \pm 60$ a.p., UGA-7976, madera carbonizada -capa 5 (6)-, 4060 \pm 90 a.p., Beta-77749, carbón -capa 4b (1a)-, 3870 \pm 90 a.p. (Beta-77748, madera) -capa 4a, zona media/base-, $3250 \pm 50$ a.p. (UGA-8354, AMS, hueso de camélido) -capa 5 (6)-, $1010 \pm 80$ a.p., Beta77750, madera -capa 4b (2)-, $960 \pm 40$ a.p. UGA-9264, carbón de limpieza de fogón -capa 1 de un basural exterior-, $530 \pm 80$ a.p., UGA-9262, gramíneas de una camada -capa 3 bajo el alero- y $460 \pm 70$ a.p., LP-869, carbón -capa 4a, cumbre. Esta secuencia de fechados señala la posible existencia de reocupaciones del sitio a lo largo del tiempo, desde cazadores recolectores en relación con la datación más temprana hasta grupos agropastoriles para las restantes, luego de un intervalo sin evidencias de utilización del sitio.

Punta de la Peña 11 (PP11) está ubicado en la parte superior del farallón de ignimbritas cerca de PP4. Se trata de una oquedad natural en la que se distinguieron acumulaciones de gramíneas, predominantemente del género Deyeuxia, cubriendo un fardo funerario que contenía un lactante momificado acompañado por cuatro cestas, dos externas al fardo, una de ellas con decoración geométrica, y dos internas tapando la cabeza. Se asocian otros elementos tales como cordeles. El conjunto a la vez se dispuso sobre otra camada de gramíneas (Aschero 1999) confeccionada con dos variedades de Deyeuxia eminens. Las dataciones radiocarbónicas realizadas indican antigüedades de 3210 \pm 50 a.p., UGA-8355, AMS, hueso humano y 3630 \pm 150 a.p., UGA-7977, gramíneas de la base del fardo funerario, comienzos del Holoceno Tardío. Este sitio fue designado con la sigla PP11-A. A pocos metros fue hallado un reparo rocoso con camadas de gramíneas y cordeles muy semejantes a las anteriores que fue denominado PP11-B. Ambos sitios corresponden a grupos cazadores recolectores tardíos.

Punta de la Peña 3 (PP3) es un caserío correspondiente, por la evidencia cerámica superficial, a asentamientos agropastoriles (Holoceno Tardío), que presenta un sector lateral (PP3-A) ubicado hacia la zona E denominada La Tranca. En este sector en donde se identificaron dos capas en la estratigrafía (capas 0 y 1 ) fue hallada una estructu- 


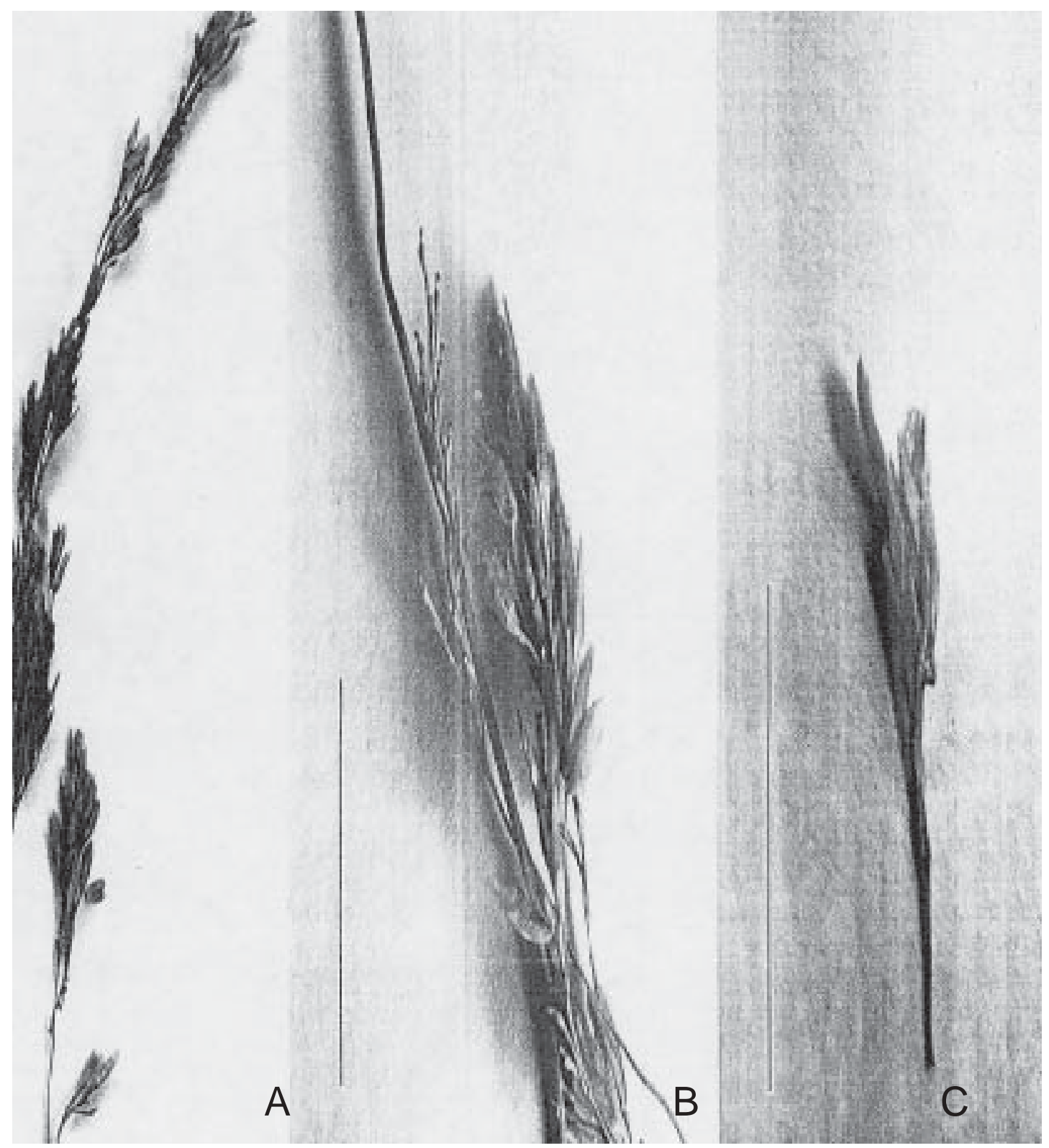

Figura 2. Deyeuxia eminens var. fulva (Griseb.) Rúgolo; especímenes recuperados en camadas de gramíneas. A-C. Inflorescencia, sitio CS1, capa 4: A, parte de la inflorescencia; B, detalle de una ramificación con espiguillas; C, espiguilla. La reglilla equivale a $1 \mathrm{~cm}$. Deyeuxia eminens var. fulva (Griseb.) Rúgolo; recovered from grass layers. A-C. Inflorescence, site CS1, layer 4: A, part of the inflorescence; $B$, detail of the branching with spikelet; $C$, spikelet. The ruler measures $1 \mathrm{~cm}$.

ra o acumulación de piedras que cubre una camada de gramíneas. En esta última se encontraron instrumentos de madera, cordeles y cerámica. Punta de la Peña 9 (PP9) es un sitio a cielo abierto con estructuras de piedra y posiblemente de adobes, con arte rupestre y restos de corrales. Una datación radiocarbónica realizada sobre semillas de Geoffrea decorticans Hook. et Arn. (chañar) indica una antigüedad de $1460 \pm 40$ a.p., UGA-9069, correspondiente a grupos agropastoriles del Holoceno Tardío.

A una distancia de 6,8 km de Punta de la Peña y a 9 km de Quebrada Seca en dirección S y SW respectivamente, se localizó el sitio Peña de la Cruz 1 (PCz1), situado en el curso medio inferior del Río Ilanco. Este sector se diferencia de los anteriores por la escasez de recursos hídricos, ya que dicho río está totalmente seco en la actualidad. 


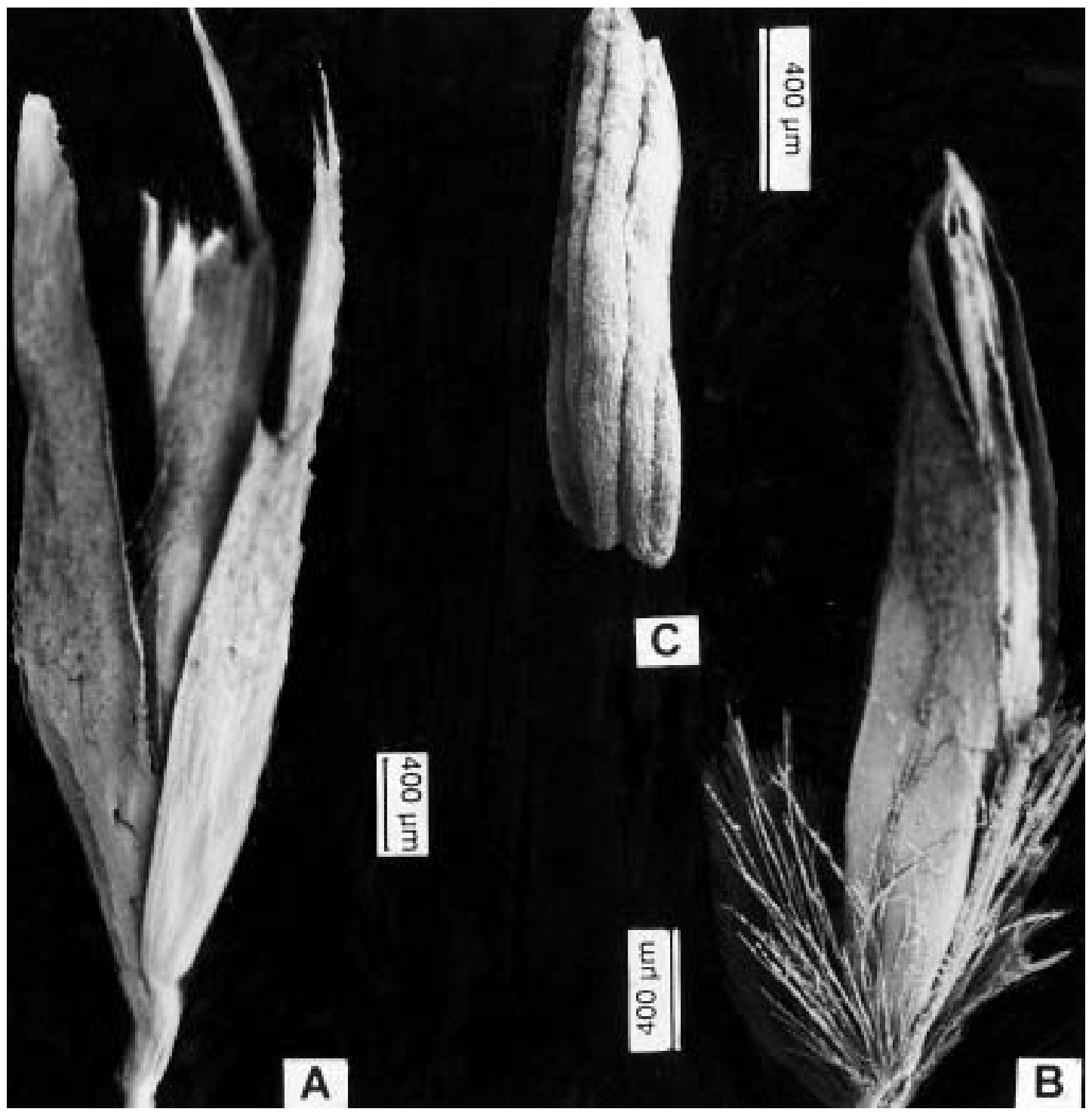

Figura 3. Órganos reproductivos recuperados en camadas de gramíneas fotografiados con Microscopio Electrónico de Barrido. AB. Deyeuxia eminens var. fulva (Griseb.) Rúgolo (sitio CS1, capa 4): A, espiguilla; B, antecio. C. Deyeuxia eminens J. Presl var. eminens, estambre (sitio QS3, nivel 2b10).

Reproductive organs recovered from grass layers and photographed using Scanning Electron Microscope. A-B. Deyeuxia eminens var. fulva (Griseb.) Rúgolo (site CS1, layer 4): A, spikelet; B, antecio. C. Deyeuxia eminens J. Presl var. eminens, stamen (site QS3, level 2b10).

PCz1 está conformado por un complejo conjunto de ocupaciones en aleros y oquedades. Por el momento se excavaron dos cuadrículas de $1 \mathrm{~m} \mathrm{x} 1 \mathrm{~m}$ en uno de los aleros pudiendo diferenciar 3 capas estratigráficas: 0, 1 y 2 (Martínez 1998-1999). La datación radiocarbónica realizada hasta la fecha, capa 2: $7270 \pm 40$ a.p., UGA-9072, carbón, permite plantear una ocupación de grupos cazadores recolectores durante el Holoceno Medio.

\section{Metodología}

El estudio de los restos vegetales hallados en sitios arqueológicos comprende la recuperación, la identificación y la interpretación de los mismos. La metodología implementada para analizar macrorrestos tomó como punto de partida el relevamiento y la identificación de las especies vegetales actuales que se desarrollan en el área de 
Tabla 1. Especies recuperadas en los sitios arqueológicos y condiciones de cada hallazgo.

A: artefacto, E: ecofacto, E/ES: ecofactos formando parte de estructuras.

Species collected from archaeological sites and their conditions of each find.

A: artifact, E: ecofact, E/ES: ecofacts forming part of structures.

\begin{tabular}{|c|c|c|c|c|c|}
\hline Especie & $\begin{array}{l}\text { Altitud } \\
(\mathrm{msm})\end{array}$ & Sitio & $\begin{array}{l}\text { Capa/ } \\
\text { nivel }\end{array}$ & $\begin{array}{l}\text { Fechado } \\
\text { (a.p.) }\end{array}$ & Material arqueológico \\
\hline D. curvula & 3500 & PP9 III & & $1460 \pm 40$ & 2 cordeles (caña). $\mathbf{A}$ \\
\hline \multirow[t]{4}{*}{ D. deserticola } & 3500 & PP3 & 1 & & 2 nudos (caña). $\mathbf{A}$ \\
\hline & 3500 & PP4 & 2 & $540 \pm 40$ & Soga (caña). A \\
\hline & 3500 & PP9 III & & $1460 \pm 40$ & $\begin{array}{l}\text { Caña. E Haces rodeando envoltura de } \\
\text { cuero (caña). A }\end{array}$ \\
\hline & 3663 & PCz1 & 2 & $7270 \pm 40$ & $\begin{array}{l}\text { Ejemplares incompletos (glumas vacías). } \\
\text { Caña y raíz. E }\end{array}$ \\
\hline \multirow[t]{16}{*}{ D. eminens var. eminens } & 4100 & QS3 & $2 \mathrm{a}$ & $2480 \pm 60$ & $\begin{array}{l}\text { Ejemplar completo con órganos } \\
\text { reproductivos. } \mathbf{E}\end{array}$ \\
\hline & & & $2 \mathrm{~b} 2$ & $4510 \pm 100$ & $\begin{array}{l}\text { Ejemplar completo con órganos } \\
\text { reproductivos. Órganos vegetativos. E } \\
\text { Camada base fardo funerario (hoja y } \\
\text { caña). E/ES }\end{array}$ \\
\hline & & & $2 \mathrm{~b} 4$ & ca. 4770 - 5380 & $\begin{array}{l}\text { Ejemplar completo con órganos } \\
\text { reproductivos. } \mathbf{E}\end{array}$ \\
\hline & & & $2 \mathrm{~b} 5$ & $5380 \pm 70$ & $\begin{array}{l}\text { Ejemplar completo con órganos } \\
\text { reproductivos. Organos vegetativos. } \mathbf{E}\end{array}$ \\
\hline & & & $2 \mathrm{~b} 10$ & ca. $7210-7130$ & $\begin{array}{l}\text { Ejemplar completo. Órganos } \\
\text { vegetativos. E }\end{array}$ \\
\hline & & & $2 b 11$ & $7130 \pm 120$ & Órganos vegetativos. E. Nudo (caña). A \\
\hline & & & $2 \mathrm{~b} 12$ & ca. $7130-7350$ & $\begin{array}{l}\text { Ejemplar completo con órganos } \\
\text { reproductivos. Órganos vegetativos. E } \\
\text { Nudo (caña). A }\end{array}$ \\
\hline & 3500 & PP3 & $0-1$ & & Caña y parte de la hoja. $\mathbf{E}$ \\
\hline & 3500 & PP4 & 0a & post. 460 & Cordel (caña). A \\
\hline & & & 2 & $540 \pm 40$ & $\begin{array}{l}\text { Hoja y caña. E. Material quemado } \\
\text { (caña) asociado con rótula y cordel. A }\end{array}$ \\
\hline & & PP4 A 5/6 & & & Hoja y parte de la panoja y espiguillas $\mathbf{E}$ \\
\hline & 3500 & PP9 III & & $1460 \pm 40$ & Hoja y caña. $\mathbf{E}$ \\
\hline & 3600 & PP11 A & & $3210 \pm 50$ & Caña. E. Haces unidos por resinas \\
\hline & & & & $3630 \pm 150$ & $\begin{array}{l}\text { (caña). A. Parte de la panoja y } \\
\text { espiguillas. E. Camadas base fardo } \\
\text { funerario (hoja y caña). E/ES }\end{array}$ \\
\hline & & PP11 B & & & Hoja y caña. $\mathbf{E}$ \\
\hline & & & & & Haces unidos por resinas (caña). $\mathbf{A}$ \\
\hline \multirow[t]{7}{*}{ D. eminens var. fulva } & 3600 & $\mathrm{CS} 1$ & 4 & ca. $7410-6250$ & Parte de la panoja y espiguillas. A \\
\hline & 3500 & PP3 & $0-1$ & & Hoja y parte de la panoja y espiguillas $\mathbf{E}$ \\
\hline & 3500 & PP4 & $2-3$ & $540 \pm 40$ & Hoja y parte de la panoja y espiguillas $\mathbf{E}$ \\
\hline & & & & $530 \pm 80$ & \\
\hline & 3500 & PP9 III & & $1460 \pm 40$ & Hoja. E. 2 cordeles (caña). $\mathbf{A}$ \\
\hline & 3600 & PP11 B & & & Nudo (hoja). A \\
\hline & 3663 & PCz1 & 2 & $7270 \pm 40$ & Hoja. $\mathbf{E}$ \\
\hline \multirow[t]{3}{*}{ D. rigescens } & 3500 & PP3 & 1 & & Caña. $\mathbf{E}$ \\
\hline & 3500 & PP9 III & & $1460 \pm 40$ & Caña. $\mathbf{E}$ \\
\hline & 3600 & PP11 A & & $\begin{array}{l}3210 \pm 50 \\
3630 \pm 150\end{array}$ & $\begin{array}{l}\text { Caña. E. Camada base fardo funerario } \\
\text { (caña). E/ES }\end{array}$ \\
\hline
\end{tabular}


estudio. La excavación por decapage sectorial de los sitios permitió la recuperación de los macrovestigios vegetales. El análisis anatómico y morfológico comparativo de las especies actuales y arqueológicas hizo posible la identificación de las últimas. De este modo se identificaron las especies pertenecientes al género Deyeuxia y se determinaron las probables áreas de procedencia de cada una de ellas. En algunos casos fue necesario obtener datos bibliográficos y consultar material de Herbario. La interpretación se realizó teniendo en cuenta el contexto de los hallazgos en los sitios arqueológicos, la información florística actual y los datos etnobotánicos. A continuación se describen los métodos y las técnicas empleadas.

\section{Material actual}

Se realizaron transectas, en distintas direcciones a partir de los sitios en estudio, durante las cuales se coleccionaron los vegetales que se desarrollan en las mismas (Figura 1). Estas especies fueron identificadas taxonómicamente y forman parte de la colección de referencia para la determinación del material arqueológico. A partir de la misma se confeccionó una histoteca que reúne los cortes histológicos de tallos y hojas del material actual, la cual se amplió con material de Herbario del Instituto de Botánica Darwinion (SI), Holmgren et al. (1990). De las especies coleccionadas interesan para este trabajo aquellas pertenecientes al género en estudio (Rúgolo de Agrasar 1999).

Para analizar las especies de Deyeuxia actuales se realizaron cortes transversales a mano alzada de la lámina de la segunda hoja caulinar en su parte media y cañas floríferas con órganos reproductivos o sin ellos. Se colorearon con safranina fast-green (D'Ambrogio de Argüeso 1986), se observaron y fotografiaron con microscopio óptico (Nikon FX-A). Este análisis permitió la identificación de las especies arqueológicas.

\section{Material arqueobotánico}

Los macrovestigios vegetales hallados en los sitios arqueológicos se diferenciaron en ecofactos $\mathrm{y}$ artefactos. Todos ellos fueron recuperados por dos de los autores de este trabajo (C. A. y F. R.) durante las excavaciones correspondientes. Frecuentemente los ecofactos forman parte de estructuras (Figuras 2 y 3 ) tales como pisos de ocupa- ción, "camas" y fardos funerarios. En otros casos, distintas especies de este género se utilizaron en la confección de nudos, cordeles, sogas y haces de gramíneas unidos con resinas. Estos artefactos fueron fotografiados con cámara fotográfica digital Nikon - Coolpix 950 (Figuras 4-6).

El material arqueobotánico fue tratado del siguiente modo:

\section{Ecofactos}

En algunos casos se encontraron especies del género Deyeuxia con órganos reproductivos, las cuales fueron identificadas taxonómicamente. Estas gramíneas pasaron a formar parte de la colección de referencia. Las hojas y cañas floríferas de estos especímenes y de las especies sin órganos reproductivos fueron tratadas del modo indicado para el material actual, no siendo posible considerar en este caso el tipo y la posición de la hoja. Además se observaron y fotografiaron algunas espiguillas utilizando Microscopio Electrónico de Barrido (Zeiss DSM 940 A) (Figura 3).

\section{Artefactos}

Se realizaron cortes a mano alzada de pequeños trozos de nudos, cordeles, sogas y haces de gramíneas unidos con resinas. Se colorearon con safranina y se observaron y fotografiaron con microscopio óptico (Nikon FX-A). Estos ejemplares pudieron identificarse por comparación a partir de la colección de referencia.

Las descripciones anatómicas se realizaron siguiendo la terminología propuesta por Metcalfe (1960) y Ellis (1976). En los casos en los que sólo se recuperaron órganos vegetativos (hojas y cañas), la anatomía analizada a partir de transcortes foliares (lámina) y caulinares (caña) permitió seleccionar los elementos celulares y tisulares para la identificación de los taxones. De esta manera, en el caso de la lámina se consideraron: forma del transcorte foliar, características de las costillas y surcos, caracteres de la epidermis abaxial y adaxial, distribución del esclerénquima subepidérmico, tipos de haces vasculares y distribución. En el caso del transcorte de las cañas floríferas, se consideraron: contorno, presencia o ausencia de costillas, distribución del esclerénquima, presencia o ausencia de clorénquima, tipo y distribución de haces vasculares y disposición del parénquima fundamental. 


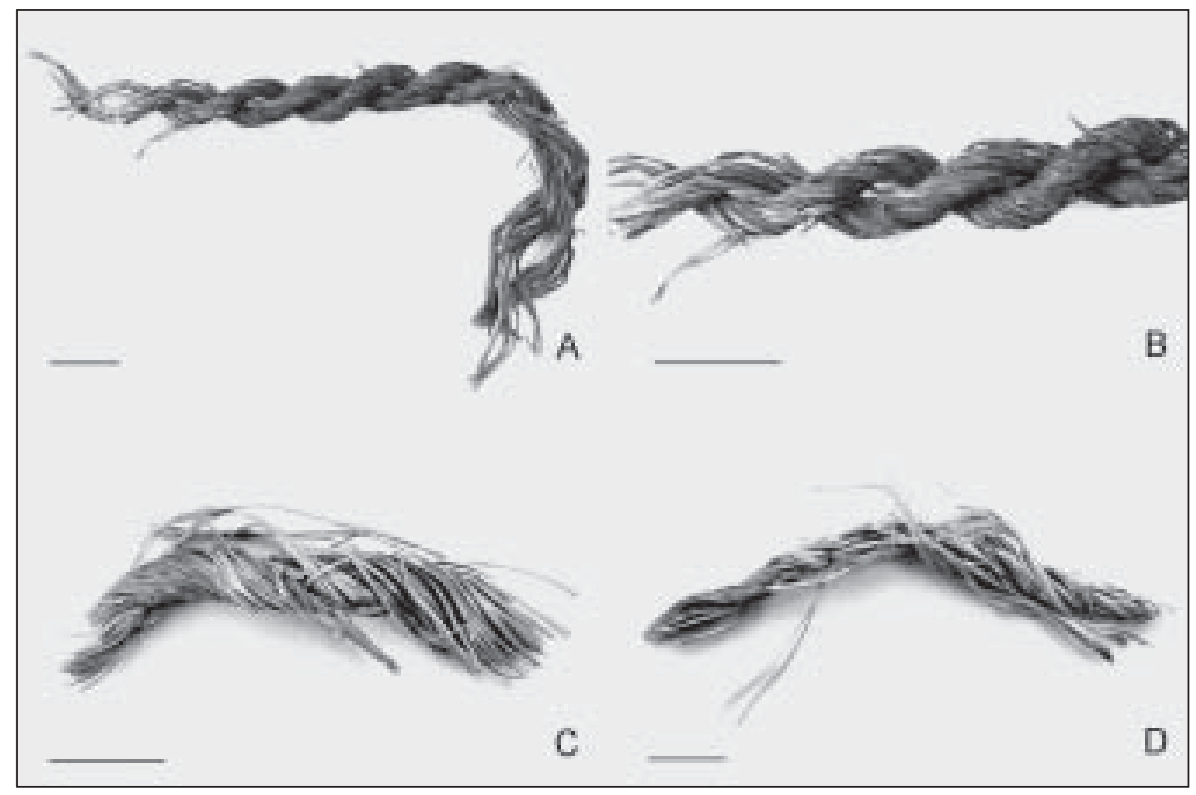

Figura 4. A-B. Deyeuxia eminens J. Presl var. eminens, cordel ( $\left.{ }^{\circ} 10\right)$, sitio PP4, capa 0A. B, detalle de A. C-D. Deyeuxia eminens var. fulva (Griseb.) Rúgolo, cordeles ( $\mathrm{N}^{\circ} 131$ y 134), sitio PP9 (estructura 2, sector III, tumba). La reglilla equivale a $1 \mathrm{~cm}$.

$A-B$. Deyeuxia eminens J. Presl var. eminens, cord ( $\left.N^{\circ} 10\right)$, site PP4, layer OA. B, detail of A. C-D. Deyeuxia eminens var. fulva (Griseb.) Rúgolo, cords ( $N^{\circ} 131$ y 134), site PP9 (structure 2, sector III, tomb). The ruler measures $1 \mathrm{~cm}$.

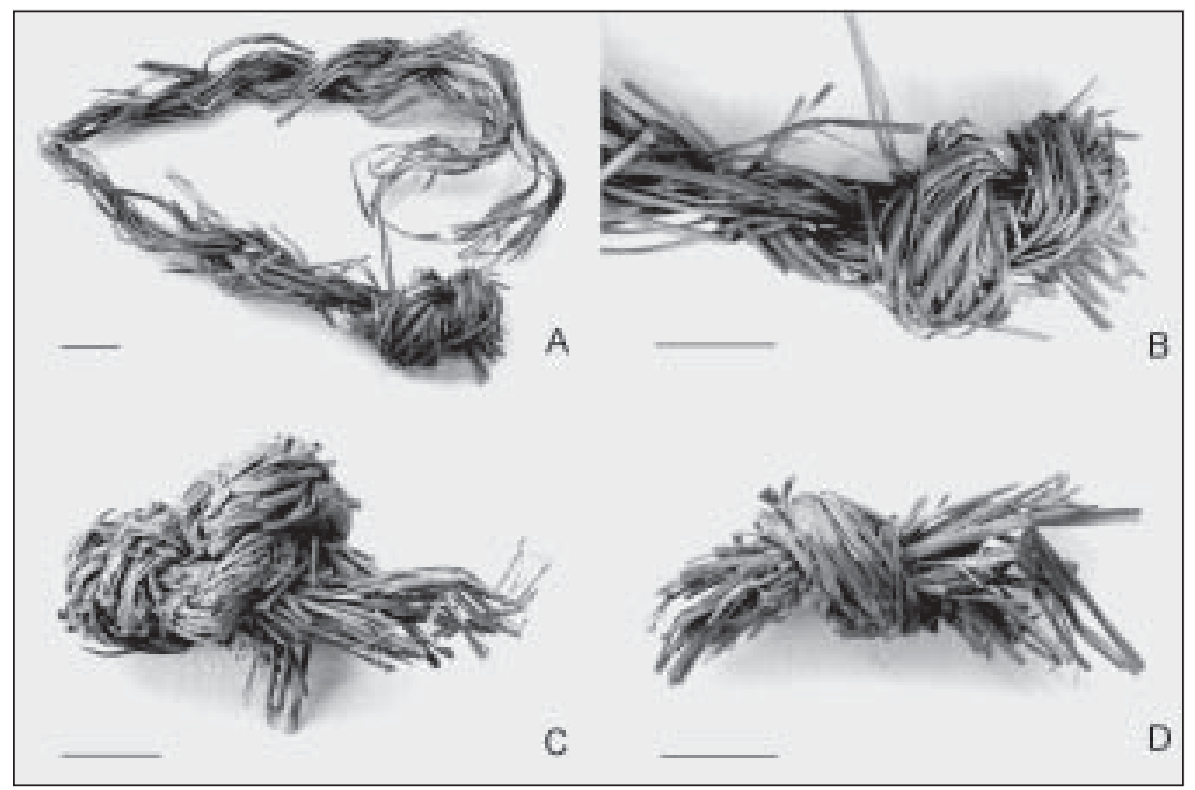

Figura 5. Deyeuxia deserticola Phil. A-B. Soga (Nº 184), sitio PP4, capa 2; B, detalle de A. C-D. Nudos $\left(\mathrm{N}^{\circ}\right.$ 2 a y b), sitio PP3. La reglilla equivale a $1 \mathrm{~cm}$.

Deyeuxia deserticola Phil. A-B. Cord ( $\left.N^{\circ} 184\right)$, site PP4, layer 2; B, detail of A. C-D. knots ( $N^{\circ} 2$ a and b), site $P$ P 3 . The ruler measures $1 \mathrm{~cm}$. 
En todos los casos se describe la anatomía foliar y caulinar, aun en aquellos en los que sólo se recuperaron cañas floríferas tales como Deyeuxia curvula, D. deserticola y D. rigescens. Esto permitió elaborar un patrón de comparación más amplio en el contexto de los taxones.

\section{Resultados}

En la Tabla 1 se destaca la presencia de Deyeuxia eminens con sus dos variedades, dominando sobre las otras especies en la mayoría de los sitios estudiados. Se señalan las condiciones de cada hallazgo. Para cada especie se describen los caracteres morfológicos y anatómicos coincidentes del material actual y arqueológico y la probable procedencia de acuerdo con el área en donde cada una de éstas ha sido coleccionada en las transectas realizadas. Deyeuxia eminens var. fulva no fue coleccionada en dichas transectas dado que su floración no coincide con la estación del año en la que se realizaron las mismas, por lo cual se consideran las posibles áreas de procedencia de acuerdo con el material de Herbario. Se describe la anatomía de la hoja y la caña florífera, aún en los casos en que alguno de estos órganos no haya sido recuperado en los sitios arqueológicos (Tabla 2). Al mismo tiempo se adjunta información referida a la distribución geográfica de los taxones. Se señala el tipo de hallazgo en relación con la clasificación adoptada (véase metodología, ecofactos y artefactos) y se consigna el número de etiquetado de los artefactos.

- Deyeuxia curvula Wedd., Bull. Soc. Bot. France 22: 178-179. 1875. Nombre vulgar: “pasto vicuña” (Figuras 6 E y 7).

Distribución geográfica. Habita desde Perú y Bolivia hasta el norte de Chile y noroeste de la Argentina. Vive en suelos húmedos, vegas y turberas de la alta Cordillera de los Andes entre 3440-4900 msm. Es una especie apetecida por los camélidos (dato consignado en etiquetas de Herbario).

Procedencia. Curso medio inferior del río Las Pitas. Transecta entre Punta de la Peña y Las Juntas (confluencia de Quebrada Seca y Quebrada de Real Grande), 3600 msm. Asociación vegetal: vega (Figura 1).
Corte transversal. Hoja (Figura 7 A-B). Transcorte de contorno redondeado. Costillas y surcos presentes en la cara adaxial. Costilla media triangular, las laterales redondeadas, costillas marginales con las caras internas más o menos paralelas entre sí. Células epidérmicas adaxiales con pared externa tangencial engrosada, células buliformes inconspicuas dispuestas en grupos regulares en los surcos y ausentes en la cara abaxial. Macropelos rígidos y cortos dispuestos en la porción distal de las costillas, sin células asociadas a la base del pelo. Estomas presentes en las caras laterales de los surcos. Células epidérmicas abaxiales con la pared tangencial externa notablemente engrosada. Generalmente siete haces vasculares, el central y dos laterales primarios, los restantes secundarios, libres, ubicados en la parte media del mesófilo. Vaina mestomática notable, vaina parenquimática inconspicua, poco desarrollada, sin cloroplastos especializados. Mesófilo con clorénquima difuso. Esclerénquima discontinuo formando paquetes subepidérmicos en la cara adaxial de las costillas, a veces ausente; esclerénquima subepidérmico abaxial formado por una o dos capas de fibras, continuo o con algunas interrupciones a nivel de los surcos; esclerénquima marginal formado por dos o tres capas de fibras, tan ancho como el haz vascular contiguo.

Corte transversal. Caña florífera (Figura 7 C-F). Caña hueca de contorno elíptico, generalmente de $1000 \mu \mathrm{m}$ long. y cerca de $600 \mu \mathrm{m}$ lat. Epidermis uniestratificada, con la pared tangencial externa más engrosada. Esclerénquima abaxial inconspicuo formado por una o dos capas de fibras. Parénquima fundamental muy abundante formado por células que aumentan gradualmente de tamaño hacia la parte central. Haces vasculares dispuestos en dos series, una interna formada por haces primarios y otra externa con haces alternos más pequeños; todos ellos rodeados por una vaina parenquimática.

\section{Material arqueológico (Figuras 6 E y 7 E-F)}

Se recuperaron dos cordeles $\left(\mathrm{N}^{\mathrm{o}} 122\right.$ y 135$)$ confeccionados con cañas floríferas de esta especie en la estructura 2, sector III (tumba) del sitio PP9. El cordel No 122 (Figuras 6 E y 7 E), parcialmente quemado, mide $2.3 \mathrm{~cm}$ de longitud; presenta dos cabos de torsión " $\mathrm{S}$ ", con dos torsiones por centímetro aproximadamente. $\mathrm{El}$ cordel $\mathrm{N}^{\mathrm{o}}$ 135 mide $5 \mathrm{~cm}$ y se encuentra muy deteriorado, 
Tabla 2. Características anatómicas foliares y caulinares de las especies del género Deyeuxia, actuales y arqueológicas (*). Current and archaeological foliar and caulinar anatomical characteristics of the genus Deyeuxia.

\begin{tabular}{|c|c|c|c|c|c|}
\hline Hoja & $\begin{array}{l}\text { D. curvula } \\
\text { Sección } \\
\text { Deyeuxia }\end{array}$ & $\begin{array}{l}\text { D. deserticola } \\
\text { Sección } \\
\text { Pungentes }\end{array}$ & $\begin{array}{l}\text { D. eminens var. } \\
\text { eminens* }^{*} \\
\text { Sección } \\
\text { Stylagrostis }\end{array}$ & $\begin{array}{c}\text { D. eminens var. } \\
\text { fulva* } \\
\text { Sección } \\
\text { Stylagrostis }\end{array}$ & $\begin{array}{c}\text { D. rigescens } \\
\text { Sección } \\
\text { Chamaecalamus }\end{array}$ \\
\hline Contorno & Redondeado & Redondeado & Forma "U" & Redondeado & Forma "V" \\
\hline Costilla media & Triangular & Triangular & Truncada & Triangular & Redondeada \\
\hline $\begin{array}{l}\text { Costillas } \\
\text { laterales }\end{array}$ & Redondeadas & Triangular & Truncadas & Redondeadas & Truncadas \\
\hline Surcos & Cara adaxial & Cara adaxial & Cara adaxial & Cara adaxial & Cara adaxial \\
\hline Margen & Caras paralelas & $\begin{array}{l}\text { Caras más o menos } \\
\text { paralelas }\end{array}$ & $\begin{array}{l}\text { Caras más o menos } \\
\text { paralelas }\end{array}$ & $\begin{array}{l}\text { Caras más o menos } \\
\text { paralelas }\end{array}$ & Redondeado \\
\hline Pelos & $\begin{array}{l}\text { Macropelos en } \\
\text { cara adaxial }\end{array}$ & $\begin{array}{l}\text { Macropelos en } \\
\text { cara adaxial }\end{array}$ & $\begin{array}{l}\text { Macropelos en } \\
\text { cara adaxial }\end{array}$ & $\begin{array}{l}\text { Macropelos en } \\
\text { cara adaxial }\end{array}$ & Ausentes \\
\hline Papilas & Ausentes & Ausentes & Cara adaxial & Cara adaxial & Ausentes \\
\hline $\begin{array}{l}\text { Células } \\
\text { papilosas en } \\
\text { epidermis } \\
\text { adaxial }\end{array}$ & Ausentes & Ausentes & Presentes & Presentes & Presentes \\
\hline $\begin{array}{l}\text { Aguijones } \\
\text { en epidermis } \\
\text { adaxial }\end{array}$ & Ausentes & Ausentes & Ausentes & Ausentes & Presentes \\
\hline $\begin{array}{l}\text { Esclerénquima } \\
\text { adaxial }\end{array}$ & Discontinuo & Ausente & Discontinuo & Discontinuo & Discontinuo \\
\hline $\begin{array}{l}\text { Esclerénquima } \\
\text { abaxial }\end{array}$ & $\begin{array}{l}\text { Continuo o } \\
\text { discontinuo }\end{array}$ & Continuo & Continuo & Continuo & Discontinuo \\
\hline Haces primarios & 3 & 6 & 5 semitrabados & 3 libres & 13-15 trabados \\
\hline $\begin{array}{l}\text { Haces } \\
\text { secundarios }\end{array}$ & 4 & 0 & 4 libres & 4 libres & 0 \\
\hline Haces trabados & Ninguno & Ninguno & Ninguno & Ninguno & Todos \\
\hline Caña & $\begin{array}{l}\text { D. curvula* } \\
\text { Sección } \\
\text { Deyeuxia }\end{array}$ & $\begin{array}{l}\text { D. deserticola* } \\
\text { Sección } \\
\text { Pungentes }\end{array}$ & $\begin{array}{l}\text { D. eminens var. } \\
\text { eminens* } \\
\text { Sección } \\
\text { Stylagrostis }\end{array}$ & $\begin{array}{c}\text { D. eminens var. } \\
\text { fulva* } \\
\text { Sección } \\
\text { Stylagrostis }\end{array}$ & $\begin{array}{l}\text { D. rigescens* } \\
\text { Sección } \\
\text { Chamaecalamus }\end{array}$ \\
\hline Contorno & $\begin{array}{l}\text { Elíptico/1000 } \mu \mathrm{m} \\
\text { long, } 600 \mu \mathrm{m} \\
\text { lat }\end{array}$ & $\begin{array}{l}\text { Elíptico / } 1072 \\
\mu \mathrm{m} \text { long, } 670 \\
\mu \mathrm{m} \text { lat }\end{array}$ & $\begin{array}{l}\text { Elíptico / } 1700 \\
\mu \mathrm{m} \text { long, } 1020 \\
\mu \mathrm{m} \text { lat }\end{array}$ & $\begin{array}{l}\text { Subcircular, } \\
\text { costillas } \\
\text { incipientes. } 450 \\
\mu \mathrm{m} \text { diám. }\end{array}$ & $\begin{array}{l}\text { Subcircular } 2210 \\
\mu \mathrm{m} \text { diám. }\end{array}$ \\
\hline $\begin{array}{l}\text { Esclerénquima } \\
\text { abaxial }\end{array}$ & 1 - 2 capas & 4 capas & 5 - 6 capas & 5 - 6 capas & 8 - 10 capas \\
\hline $\begin{array}{l}\text { Haces } \\
\text { vasculares }\end{array}$ & 2 series & 2 series & 2 series & 2 series & 3 - 4 series \\
\hline $\begin{array}{l}\text { Clorénquima } \\
\text { subepidérmico }\end{array}$ & Ausente & Ausente & Ausente & Presente & Ausente \\
\hline $\begin{array}{l}\text { Parénquima } \\
\text { Medular } \\
\text { Fundamental }\end{array}$ & $\begin{array}{l}\text { Muy abundante. } \\
4 / 5 \text { partes del } \\
\text { espesor total de } \\
\text { la caña }\end{array}$ & $\begin{array}{l}\text { Abundante. } 2 / 3 \\
\text { partes del espesor } \\
\text { total de la caña }\end{array}$ & $\begin{array}{l}\text { Abundante. } 3 / 4 \\
\text { partes del espesor } \\
\text { total de la caña }\end{array}$ & $\begin{array}{l}\text { Escaso. } 1 / 3 \text { parte } \\
\text { del espesor total } \\
\text { de la caña }\end{array}$ & $\begin{array}{l}\text { Abundante. } 3 / 4 \\
\text { partes del espesor } \\
\text { total de la caña }\end{array}$ \\
\hline
\end{tabular}




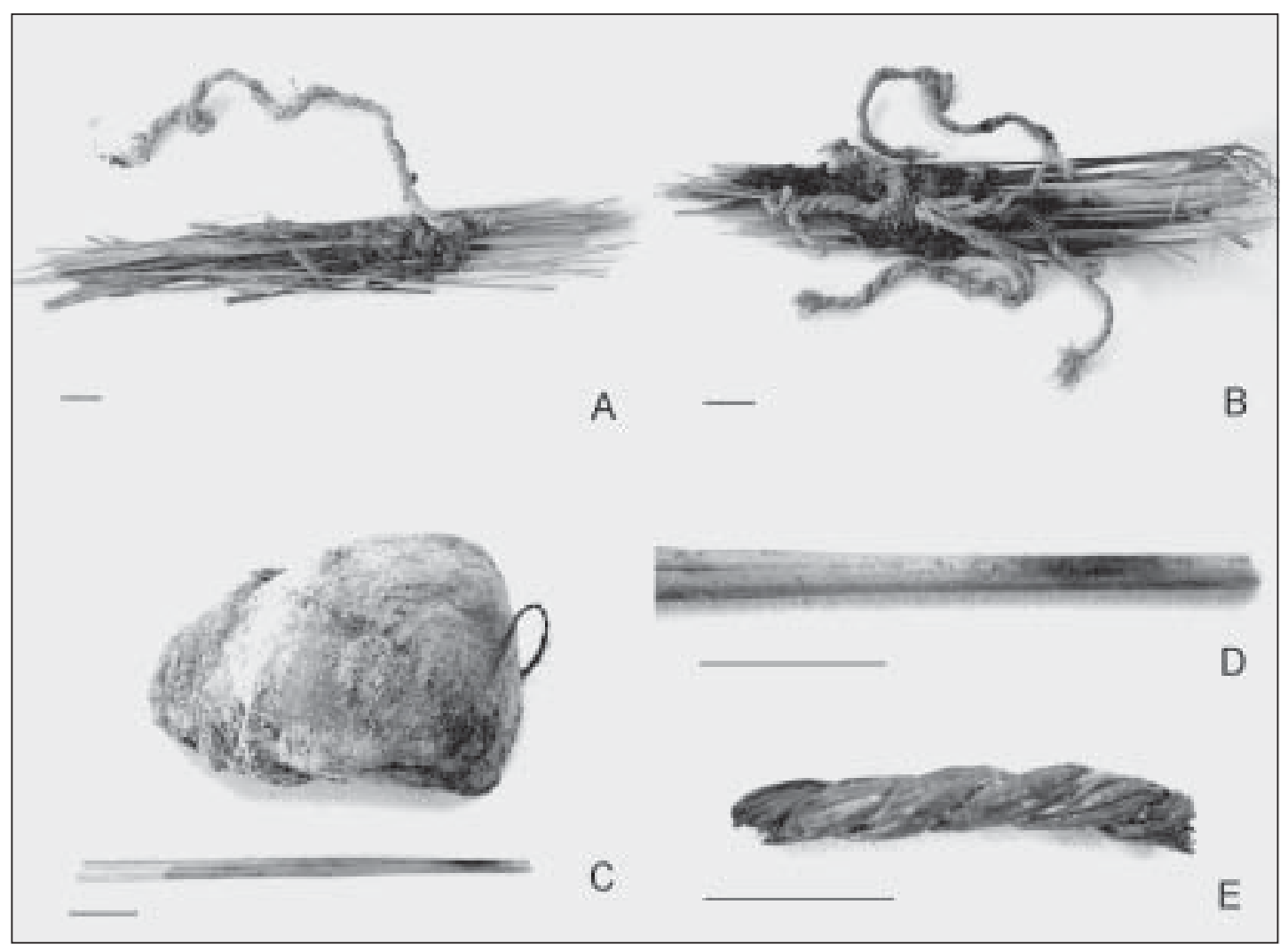

Figura 6. A-D. Deyeuxia eminens J. Presl var. eminens: A-B, cañas floríferas unidas con resinas, sitio PP11-B (N²3 y 24); C-D, caña quemada ( $\left.\mathrm{N}^{\circ} 191\right)$ asociada con rótula y cordel de lana, sitio PP4, capa 2; E. Deyeuxia curvula Wedd., cordel (N $\left.^{\circ} 122\right)$, sitio PP9 estructura 2, sector III, tumba. La reglilla equivale a $1 \mathrm{~cm}$.

$A-D$. Deyeuxia eminens J. Presl var. eminens: A-B, flowering culms bundled with resins, site PP11-B ( $N^{\circ} 23$ and 24); $C$-D, burned cane $\left(N^{\circ} 191\right)$ associated with kneecap camelid fiber yarn, site PP4, layer 2 ; E. Deyeuxia curvula Wedd., cord ( $\left.N^{\circ} 122\right)$, site PP9 structure 2, sector III, tomb. The ruler measures $1 \mathrm{~cm}$.

motivo por el cual no es posible precisar sus características.

- Deyeuxia deserticola Phil., Florula Atacamensis: 55. 1860 (Figuras 5 y 8).

Distribución geográfica. Propia de regiones altoandinas de la Puna de Chile, Argentina y Bolivia. Vive en cercanías de vegas, lagunas salitrosas y roquedales entre $3600-4900 \mathrm{msm}$.

Procedencia. Transecta Quebrada de Ilanco-Vega de Ilanco, 3500-3900 msm. Asociaciones vegetales: tolar y vega (Figura 1).

Corte transversal. Hoja (Figura 8 A-B). Transcorte de contorno redondeado. Costillas y surcos presentes en la cara adaxial. Costillas triangulares semejantes; costillas marginales con las caras internas más o menos paralelas entre sí. Células epidérmi- cas adaxiales con pared externa tangencial engrosada, células buliformes inconspicuas dispuestas en grupos regulares en los surcos y ausentes en la cara abaxial. Macropelos rígidos y cortos dispuestos en la porción distal de las costillas, sin células asociadas con la base del pelo. Estomas presentes en las caras laterales de los surcos. Células epidérmicas abaxiales con la pared tangencial externa notablemente engrosada. Generalmente seis haces vasculares primarios, libres, ubicados en la parte media del mesófilo. Vaina mestomática notable; vaina parenquimática inconspicua, poco desarrollada, sin cloroplastos especializados. Mesófilo con clorénquima difuso. Esclerénquima subepidérmico abaxial continuo formado por una o dos capas de fibras; esclerénquima marginal formado por dos o tres capas de fibras, más ancho que el haz vascular contiguo. 
Observación. Según Villavicencio (1995) el haz vascular medio y los dos laterales pueden ser semitrabados con esclerénquima abaxial.

Corte transversal. Caña florífera (Figura 8 C-E). Caña hueca de contorno elíptico, generalmente de $1072 \mu \mathrm{m}$ long. y $670 \mu \mathrm{m}$ lat. Epidermis uniestratificada, con la pared tangencial externa más engrosada. Esclerénquima abaxial conspicuo formado por cuatro capas de fibras. Parénquima fundamental abundante formado por células que aumentan gradualmente de tamaño hacia la parte central. Haces vasculares dispuestos en dos series, una interna formada por haces primarios y otra externa con haces alternos más pequeños; todos ellos rodeados por una vaina parenquimática de paredes engrosadas.

\section{Material arqueológico (Figuras 5 y 8 D-E)}

En la capa 1 del sitio PP3 se recuperaron dos nudos ( $\left.\mathrm{N}^{\circ} 2 \mathrm{a}-\mathrm{b}\right)$ confeccionados con cañas floríferas. El $\mathrm{N}^{\circ} 2$ a es un nudo realizado en la porción terminal de un cordel y mide $3,5 \mathrm{~cm}$ x 2,5 cm x $2 \mathrm{~cm}$ (Figura $5 \mathrm{C}$ ). El No $2 \mathrm{~b}$ presenta un solo cabo de torsión "S" y mide $3,5 \mathrm{~cm}$ x $1 \mathrm{~cm}$ x $0,8 \mathrm{~cm}$ (Figura $5 \mathrm{D}$ ).

En la capa 2 del sitio PP4, el ejemplar No 184 es una soga elaborada utilizando cañas floríferas, con 7-8 cabos de torsión "S". La misma presenta un nudo en uno de sus extremos, habiéndose perdido probablemente el del otro extremo. Este artefacto mide $15 \mathrm{~cm}$ de longitud y el nudo mencionado $1,5 \mathrm{~cm}$ x $1,5 \mathrm{~cm} \times 0,8 \mathrm{~cm}$ (Figuras $5 \mathrm{~A}-\mathrm{B}$ y $8 \mathrm{E}$ ).

En la estructura 2, sector 3 (tumba) del sitio PP9 fueron hallados órganos vegetativos (cañas) formando parte de los pisos de ocupación y un haz de gramíneas $\left(\mathrm{N}^{\circ} 132\right)$ constituido por cañas de la misma especie, rodeando una envoltura de cuero.

Por último, en el sitio PCz1 ejemplares de esta especie, sin órganos reproductivos (glumas vacías), forman grandes camadas que constituyen los pisos de ocupación en la capa 2 (Figura 8 D).

- Deyeuxia eminens J. Presl, Rel. Haenk. 1: 250. 1830.

- D. eminens var. eminens. Nombre vulgar: pasto huailla, huaya, iru, sora sora (Figuras 3 C, 4 A-B, 6 A-D y 9).
Distribución geográfica. Habita desde Colombia hasta el noroeste de la Argentina. Vive en lugares húmedos, cenagosos, en vegas y en altas montañas entre $3000-4730 \mathrm{msm}$.

Procedencia. Márgenes del río Punilla, 3400 msm; a $16 \mathrm{~km}$ de Punta de la Peña y $20 \mathrm{~km}$ de Quebrada Seca (Figura 1).

Corte transversal. Hoja (Figura 9A-B). Transcorte en forma de "U". Costillas y surcos profundos en la cara adaxial. Costillas truncadas, grandes y pequeñas alternas; costillas marginales con las caras internas más o menos paralelas entre sí. Células epidérmicas adaxiales con pared externa tangencial engrosada alternando con células papilosas; células buliformes conspicuas dispuestas en grupos regulares en los surcos y ausentes en la cara abaxial. Macropelos rígidos y cortos dispuestos en la porción distal de las costillas, sin células asociadas con la base del pelo. Papilas notablemente desarrolladas. Estomas presentes en las caras laterales de los surcos. Células epidérmicas abaxiales con la pared tangencial externa notablemente engrosada alternando con aguijones. Generalmente nueve haces vasculares, el central y cuatro laterales primarios semitrabados, los restantes secundarios, libres, más próximos a la cara abaxial. Vaina mestomática notable, vaina parenquimática inconspicua, poco desarrollada, sin cloroplastos especializados. Mesófilo con clorénquima difuso. Esclerénquima discontinuo formando paquetes subepidérmicos en la cara adaxial de las costillas no vinculado a los haces vasculares; esclerénquima abaxial subepidérmico formado por tres o cuatro capas de fibras, continuo en vinculación con los haces primarios; esclerénquima marginal formado por dos o tres capas de fibras.

Corte transversal. Caña florífera (Figura 9 C-H). Caña hueca de contorno elíptico, generalmente de $1700 \mu \mathrm{m}$ long. y cerca de $1020 \mu \mathrm{m}$ lat. Epidermis uniestratificada, con la pared tangencial externa más engrosada. Esclerénquima abaxial conspicuo formado por cinco o seis capas de fibras. Parénquima fundamental abundante formado por células que aumentan gradualmente de tamaño hacia la parte central. Haces vasculares dispuestos en dos series, una interna formada por haces primarios y otra externa con haces alternos más pequeños; todos ellos rodeados por una vaina parenquimática de paredes engrosadas. 

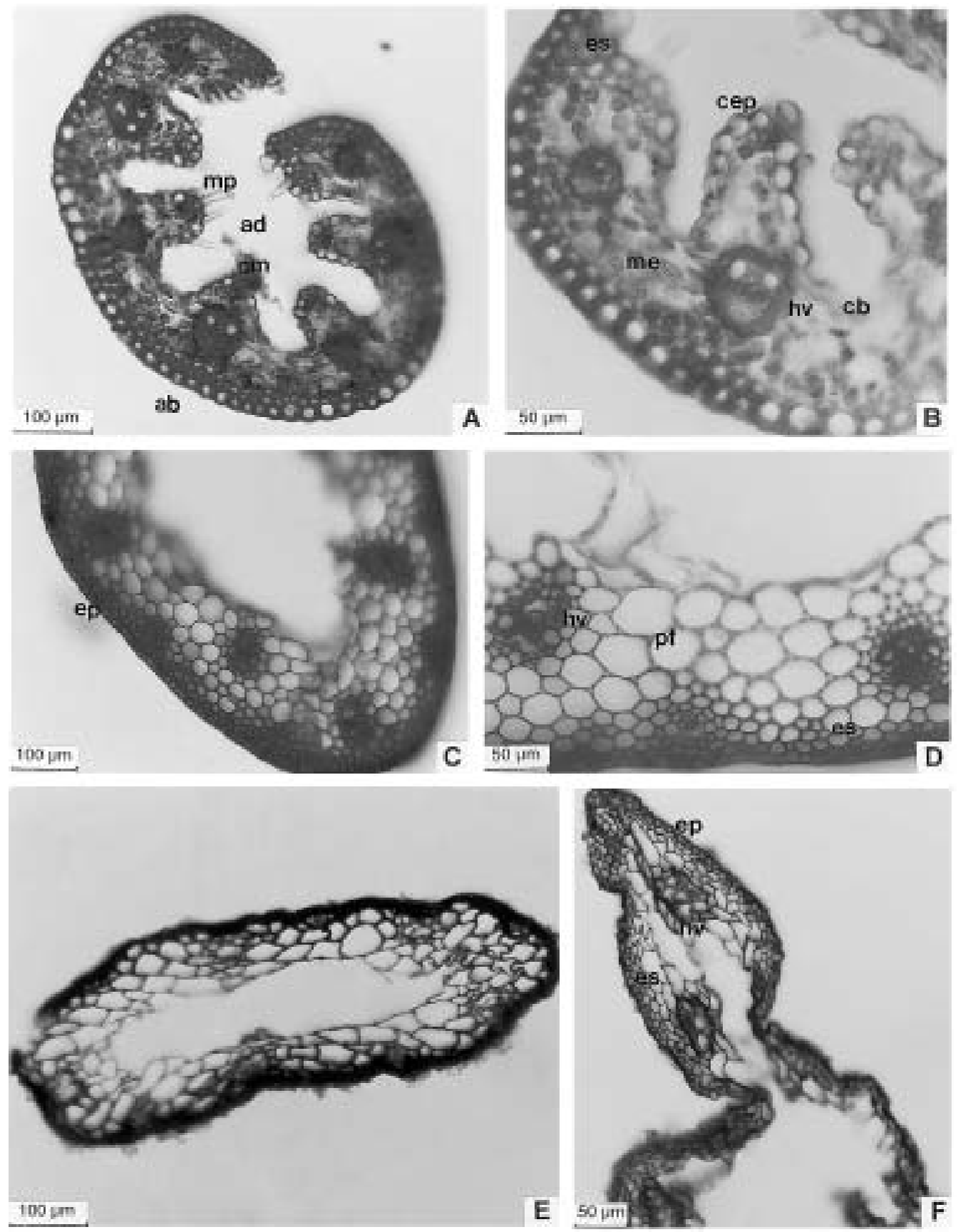

Figura 7. Deyeuxia curvula Wedd. A-D. Material actual: A-B, J. Hunziker \& O. Caso 4114; C-D: Rodríguez 16: A, corte transversal completo de lámina; B, detalle de A, nervio medio y costillas laterales; C, corte transversal de caña florífera; D, detalle de C. E-F. Material arqueológico del sitio PP9, corte transversal de caña florífera: E, cordel parcialmente quemado ( $\left.\mathrm{N}^{\circ} 122\right)$; F, cordel ( $\left.\mathrm{N}^{\circ} 135\right)$. Fotografías obtenidas con microscopio óptico (ab, cara abaxial; ad, cara adaxial; $\mathrm{cb}$, célula buliforme; cep, célula epidérmica; $\mathrm{cm}$, costilla media; ep, epidermis; es, esclerénquima; hv, haz vascular; me, mesófilo; mp, macropelos; pf, parénquima fundamental).

Deyeuxia curvula Wedd. A-D. Current material: A-B, J. Hunziker \& O. Caso 4114; C-D: Rodríguez 16 : A, complete transversal section of the lamina; $B$, detail of $A$, medial nerve and lateral ribs; $C$, transversal section of flowering cane; $D$, detail of C. E-F. Archaeological material of site PP9, transversal section of flowering culms: E, partially burned cord $\left(N^{\circ} 122\right) ; F$, cord $\left(N^{\circ} 135\right)$. ab, abaxial face; ad, adaxial face; cb, buliform cell; cep, epidermis cell; cm, medial rib; ep, epidermis; es, sclerenchyma; $h v$, vascular bundle; me, mesofilo; mp, macro hairs; pf, basic parenchyma. The photographs were taken using an optical microscope. 


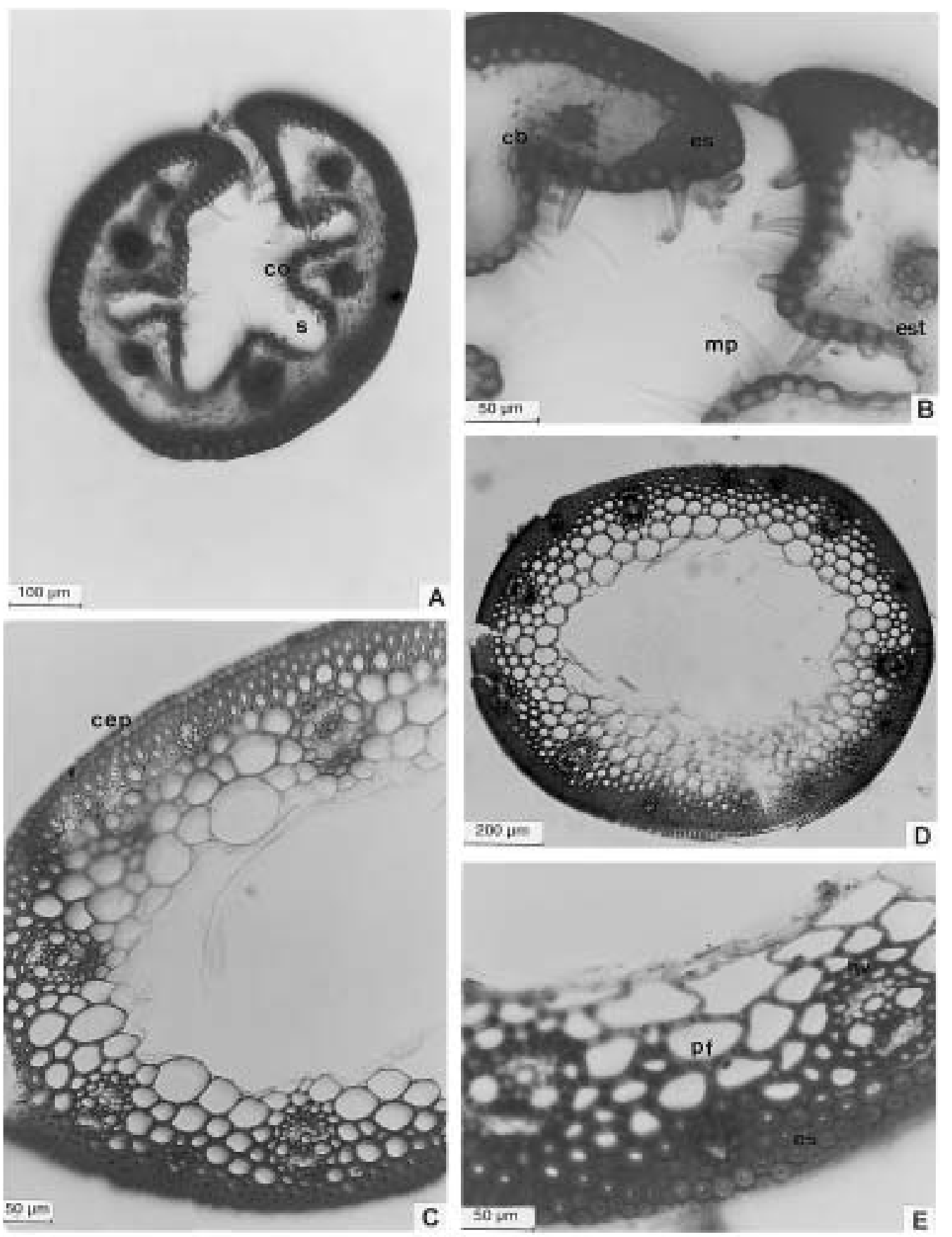

Figura 8. Deyeuxia deserticola Phil. A-C. Material actual, Cabrera et al. 31813 y Rodríguez, s.n. (SI): A, corte transversal completo de lámina; B, detalle de A a nivel de las márgenes foliares; C, corte transversal de caña florífera. D-E. Material arqueológico: D, corte transversal de caña florífera recuperada en camada de gramíneas, sitio PCz1, capa 2; E, corte transversal de caña florífera, parte de una soga ( $\left.\mathrm{N}^{\circ} 184\right)$, sitio PP4, capa 2. Fotografías obtenidas con microscopio óptico (cb, célula buliforme; cep, célula epidérmica; co, costilla; es, esclerénquima; hv, haz vascular; mp, macropelos; pf, parénquima fundamental; $\mathrm{s}$, surco).

Deyeuxia deserticola Phil. A-C. Current material, Cabrera et al. 31813 and Rodríguez, SI: A, complete transversal section; $B$, detail of $A$ at foliar margins; $C$, transversal cut of the flowering culms. D-E. Archaeological material: $D$, transversal section of flowering culms taken from a grass strata, site PCz1, layer 2; E, transversal section of flowering culms, part of rope ( $\left.N^{\circ} 184\right)$, site PP4, layer 2. cb, buliform cell; cep, epidermis cell; co, rib; es, sclerenchyma; hv, vascular bundle; mp, macro hair; pf, basic parenchyma; s, sulcus. The photographs were taken using an optical microscope. 
Material arqueológico (Figuras 3 C, 4 A-B, 6 A-D y 9 D-H)

En el sitio QS3 (capa 2a y 2b, niveles 2, 4, 5, 10 y 12) se recuperaron especímenes completos con órganos vegetativos y reproductivos. En el nivel 2 de la capa $2 \mathrm{~b}$ una camada integrada por hojas y cañas floríferas con órganos reproductivos ( $\mathrm{Fi}-$ gura 3 C) sirvió de base para un fardo funerario (Rodríguez y Rúgolo de Agrasar 1999). En los niveles $5,10,11$ y 12 de la misma capa los órganos vegetativos mencionados formaron parte de camadas que constituyeron pisos de ocupación en los tres primeros niveles mencionados y una "cama" en el último. En los niveles 11 y 12 fueron hallados dos nudos ( $\mathrm{N}^{\circ} 200$ y 431) confeccionados con cañas floríferas de esta especie (Rodríguez y Rúgolo de Agrasar 1999).

En los sitios PP3 (capas 0 y 1) (Figura 9 D), PP4 (capa 2 y sector A 5/6) y PP9 (estructura 2, sector III, tumba) los órganos vegetativos (hoja y caña florífera sin órganos reproductivos) de esta especie formaron parte de los pisos de ocupación. En PP11-A estas estructuras vegetativas sirvieron de base para apoyar el fardo funerario descrito anteriormente y en PP11-B constituyeron una "cama".

En PP4 (sector A 5/6) y en PP11-A se recuperaron partes de la panoja y espiguillas. Los caracteres de las espiguillas coinciden con lo descrito para esta especie en el sitio QS3 (Rodríguez y Rúgolo de Agrasar 1999). En el último sitio los órganos reproductivos (panoja y espiguillas) junto con los vegetativos de esta especie (hoja y caña florífera sin órganos reproductivos) formaron parte de la base del fardo funerario descrito.

En el sitio PP4 (capa 0-a) fue hallado un cordel ( $\left.N^{\circ} 10\right)$ confeccionado con cañas floríferas de esta especie (Figuras 4 A-B y 9 G). Este presenta siete cabos de torsión "S" y mide $11 \mathrm{~cm}$ de longitud, con una torsión cada $0,5 \mathrm{~cm}$. En la capa 2 del mismo sitio se encontró una caña florífera quemada $\left(\mathrm{N}^{\circ} 191\right)$ de $6,5 \mathrm{~cm}$ de longitud asociada con una rótula rodeada por un cordel de lana (Figuras 6 C-D y 9 E).

En los sitios PP11-A ( $\mathrm{N}^{\circ} 21$ y 22) y B $\left(\mathrm{N}^{\circ} 23\right.$ y 24) (Figuras 6 A-B y 9 H) las cañas floríferas de esta especie forman parte de haces unidos por resinas que aparecen acompañados por largos cordeles confeccionados con Acrocomia sp. (Palmae). En PP11-B esta especie fue utilizada también para confeccionar un cordel ( $\mathrm{N}^{\circ} 24$; Figura $9 \mathrm{~F}$ ).
- D. eminens var. fulva (Griseb.) Rúgolo, Bol. Soc. Argent. Bot. 30: 112. 1994. Nombre vulgar: pasto de vega, cebadilla de vicuña (Figuras $2,3 \mathrm{~A}-\mathrm{B}, 4 \mathrm{C}-\mathrm{D}, 10$ y 11 ).

Distribución geográfica. Vive en el norte de Chile y en la Argentina desde Jujuy hasta Mendoza. Habita en vegas y a orillas de arroyos entre 3200-4200 msm.

Procedencia. Material de Herbario. Argentina. Provincia de Catamarca, Depto. Belén, Laguna Blanca, 4200 msm, 16-III-1989, Reca et Ramadori 136 y 141 (SI).

Corte transversal. Hoja (Figura 10). Transcorte de contorno redondeado. Costillas y surcos profundos en la cara adaxial. Costilla media triangular y las laterales redondeadas; costillas marginales con las caras internas más o menos paralelas entre sí. Células epidérmicas adaxiales con pared externa tangencial engrosada alternando con células papilosas; células buliformes conspicuas dispuestas en grupos regulares en los surcos y ausentes en la cara abaxial. Macropelos rígidos y papilas prominentes. Estomas presentes en las caras laterales de los surcos. Células epidérmicas abaxiales con la pared tangencial externa notablemente engrosada alternando con aguijones. Generalmente siete haces vasculares libres, el central y dos laterales primarios alternando con los secundarios, más próximos a la cara abaxial. Vaina mestomática notable, vaina parenquimática inconspicua, poco desarrollada, sin cloroplastos especializados. Mesófilo con clorénquima difuso. Esclerénquima discontinuo formando paquetes subepidérmicos en la cara adaxial de las costillas no vinculado a los haces vasculares; esclerénquima abaxial subepidérmico formado por tres o cuatro capas de fibras, continuo; esclerénquima marginal formado por dos o tres capas de fibras.

Corte transversal. Caña florífera (Figura 11). Caña hueca de contorno subcircular con costillas redondeadas incipientes, generalmente de $450 \mu \mathrm{m}$ de diámetro. Epidermis uniestratificada, con la pared tangencial externa más engrosada. Esclerénquima abaxial conspicuo formado por cinco o seis capas de fibras. Clorénquima subepidérmico representado por dos grupos de células a ambos lados de los haces vasculares más pequeños. Parénquima fundamental escaso formado por células que aumentan gradualmente de tamaño hacia la parte central. 
Haces vasculares dispuestos en dos series, una interna formada por haces primarios incluidos en el parénquima fundamental y otra externa con haces alternos más pequeños; todos ellos rodeados por una vaina parenquimática de paredes engrosadas.

Material arqueológico (Figuras 2, 3 A-B, 4 C-D, $10 \mathrm{C}-\mathrm{F}$ y $11 \mathrm{C}$ )

En los sitios CS1, PP3 (capas 0 y 1) y PP4 (capas 2 y 3 ) fueron halladas partes de la panoja y espiguillas de esta especie (Figuras 2 y 3 A-B). Por lo general se recuperaron inflorescencias incompletas donde se aprecian ramificaciones laterales con espiguillas dispuestas en su parte distal. Las mismas presentan glumas membranáceas, doradas, brillantes, de 3,5 a $5 \mathrm{~mm}$ de longitud. En muchos casos se encuentra también el antecio de igual consistencia y color, de 2,5 a 3,5 mm de longitud. Una característica de esta especie es el artejo inferior de la raquilla prolongado, hasta de $0,8 \mathrm{~mm}$ de longitud que se hace notoriamente visible cuando las glumas caen tardíamente (Figura 2 B). En PP3, PP4, en la estructura 2 (sector III, tumba) de PP9 y en PCz1 se agregan órganos vegetativos (hojas) formando parte en todos los casos de los pisos de ocupación (Figura 10 C-D).

En la estructura 2 (sector III, tumba) del sitio PP9 se recuperaron dos cordeles ( $\mathrm{N}^{\mathrm{o}} 131$ y 134$)$. El primero forma parte de la atadura de un paquete de cuero; fue confeccionado simplemente torciendo cañas floríferas de esta especie y mide $4,3 \mathrm{~cm}$ de longitud (Figuras $4 \mathrm{C}$ y $11 \mathrm{C}$ ). El segundo elaborado del mismo modo, mide $7 \mathrm{~cm}$ de longitud (Figura $4 \mathrm{D}$ ).

En el sitio PP11-B se encontró un nudo $\left(\mathrm{N}^{\circ}\right.$ 20) realizado con hojas de esta especie utilizando un torsión muy simple, ya que se deshizo fácilmente al seleccionar material para realizar el corte transversal para su identificación. Por ese motivo no es posible describirlo detalladamente (Figura $10 \mathrm{E}-\mathrm{F})$.

- Deyeuxia rigescens (J. Presl) Türpe, Lilloa 31: 134. 1960 (Figura 12)

Distribución geográfica. Vive desde Ecuador hasta el noroeste de la Argentina. Habita en vegas, ciénagas, bordes de arroyos y ríos, en regiones altoandinas entre $3000-4700 \mathrm{msm}$.

Procedencia. Curso medio inferior del río Las Pi- tas. Transecta entre Punta de la Peña y Las Juntas, $3800 \mathrm{msm}$. Asociación vegetal: vega (Figura 1).

Corte transversal. Hoja (Figura 12 A). Transcorte en forma de "V". Costillas y surcos profundos en la cara adaxial. La costilla media redondeada, menor que las laterales truncadas. Células epidérmicas adaxiales con paredes delgadas alternando con células papilosas redondeadas y aguijones pequeños; células buliformes conspicuas dispuestas en grupos regulares en los surcos y ausentes en la cara abaxial. Estomas presentes en las caras laterales de los surcos. Células epidérmicas abaxiales con la pared tangencial externa notablemente engrosada. Generalmente 13-15 haces vasculares, trabados, más próximos a la cara abaxial. Vaina mestomática notable, vaina parenquimática inconspicua, poco desarrollada, sin cloroplastos especializados. Mesófilo con clorénquima difuso. Esclerénquima discontinuo formando trabas esclerenquimáticas adaxiales y abaxiales en vinculación con los haces vasculares; esclerénquima marginal formado por dos o tres capas de fibras.

Corte transversal. Caña florífera (Figura 12 B-D). Caña hueca de contorno redondeado, generalmente de $2210 \mu \mathrm{m}$ de diámetro. Epidermis uniestratificada, con la pared tangencial externa más engrosada. Esclerénquima abaxial conspicuo formado por ocho a diez capas de fibras. Parénquima fundamental abundante formado por células que aumentan gradualmente de tamaño hacia la parte central. Haces vasculares dispuestos en tres o cuatro series alternas, la externa con haces más pequeños; todos ellos rodeados por una vaina parenquimática de paredes engrosadas.

\section{Material arqueológico (Figura 12 D)}

En los sitios PP3 (capa 1) y PP9 (estructura 2, sector III, tumba) fueron halladas cañas floríferas de esta especie formando parte de los pisos de ocupación. En PP11-A, las mismas sirvieron de base para el fardo funerario descrito anteriormente (Figura $12 \mathrm{D})$.

\section{Discusión y Conclusiones}

Las especies halladas del género Deyeuxia pertenecen a cuatro secciones: Deyeuxia, 

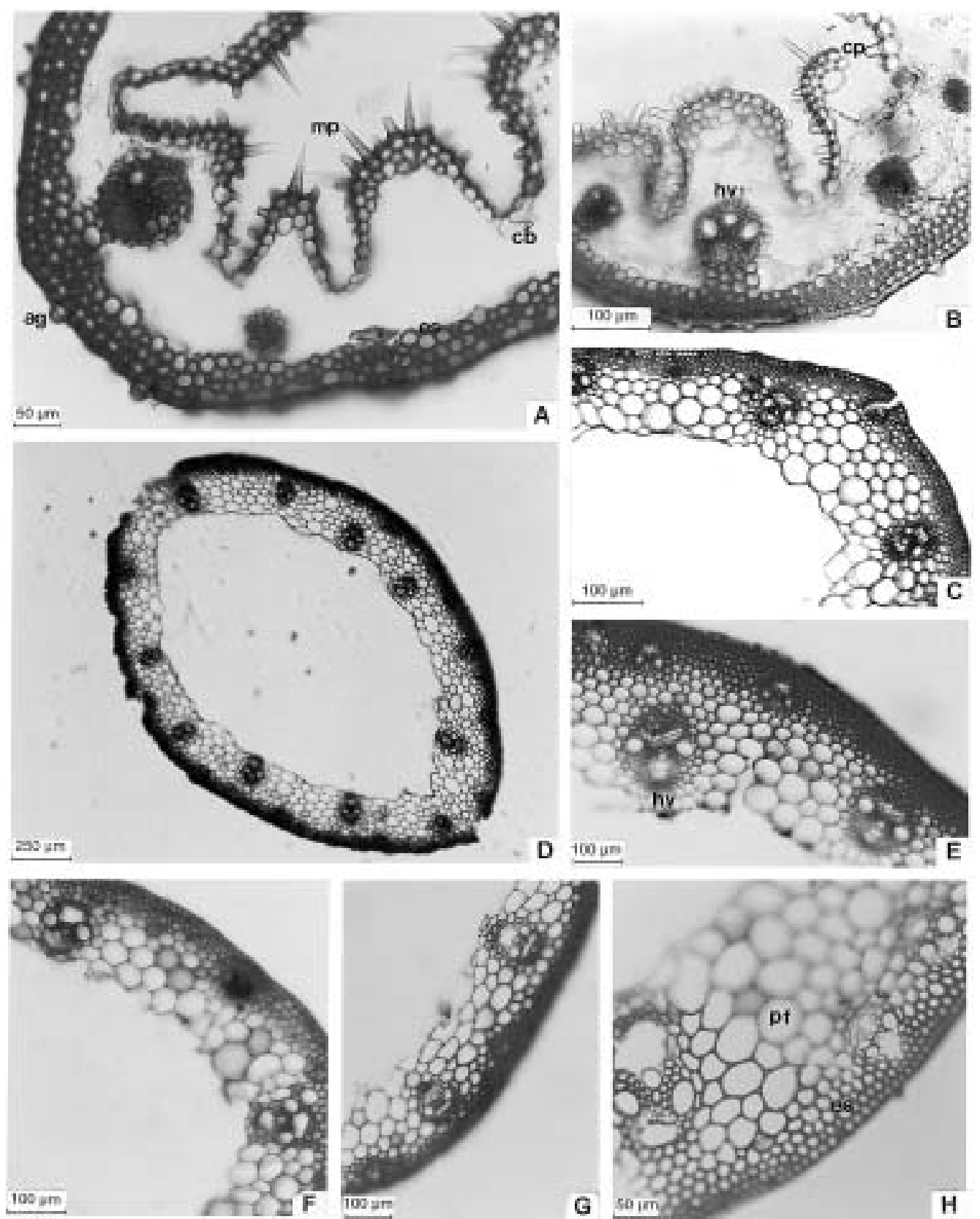

Figura 9. Deyeuxia eminens J. Presl var. eminens. A-B. Corte transversal incompleto de lámina: A, material arqueológico, sitio PP4 A5/6; B, material actual. C. Corte transversal de caña florífera, material actual. B-C: Cabrera et al. 31818 D-H. Corte transversal de caña florífera, material arqueológico: D, caña recuperada en camada de gramíneas, sitio PP3, capa 0; E, caña quemada asociada con rótula y cordel de lana ( $\left.\mathrm{N}^{\circ} 191\right)$, sitio PP4, capa 2; F, cordel ( $\left.\mathrm{N}^{\circ} 24\right)$, sitio PP11$\mathrm{B} ; \mathrm{G}$, cordel $\left(\mathrm{N}^{\circ} 10\right)$, sitio PP4, capa 0 ; H, cañas floríferas unidas con resinas ( $\mathrm{N}^{\circ} 23$ y 24), sitio PP11-B. Fotografías obtenidas con microscopio óptico (ag, aguijones; cb, célula buliforme; cp, célula papilosa; es, esclerénquima; hv, haz vascular; hv1, haz vascular primario; mp, macropelo; pf, parénquima fundamental).

Deyeuxia eminens J. Presl var. eminens. A-B. Incomplete transversal thin section: A, archaeological material, site PP4 A5/6; B, current material. C. Transversal cut of flowering culms, modern material. B-C: Cabrera et al. 31818. D-H. Transversal cut of flowering culms, archaeological material: D, Culms recovered from a bed of grass strata, site PP3, layer $0 ; E$, burned culms in association with kneecap and camelid fiber yarn $\left(N^{\circ} 191\right)$, site PP4, layer $2 ; F$, cord $\left(N^{\circ} 24\right)$, site PP11-B; G, cord ( $\left.N^{\circ} 10\right)$, site PP4, layer 0; $H$, Flowering culms bundled together with resins $\left(N^{\circ} 23\right.$ y 24), site PP11-B. ag, thorns; cb, buliform cells; $c$ p, papilose cell; es, sclerenchyma; $h v$, vascular bundle; hv1, primary vascular bundle; mp, macro hair; pf, basic parenchyma The photographs were taken using an optical microscope. 

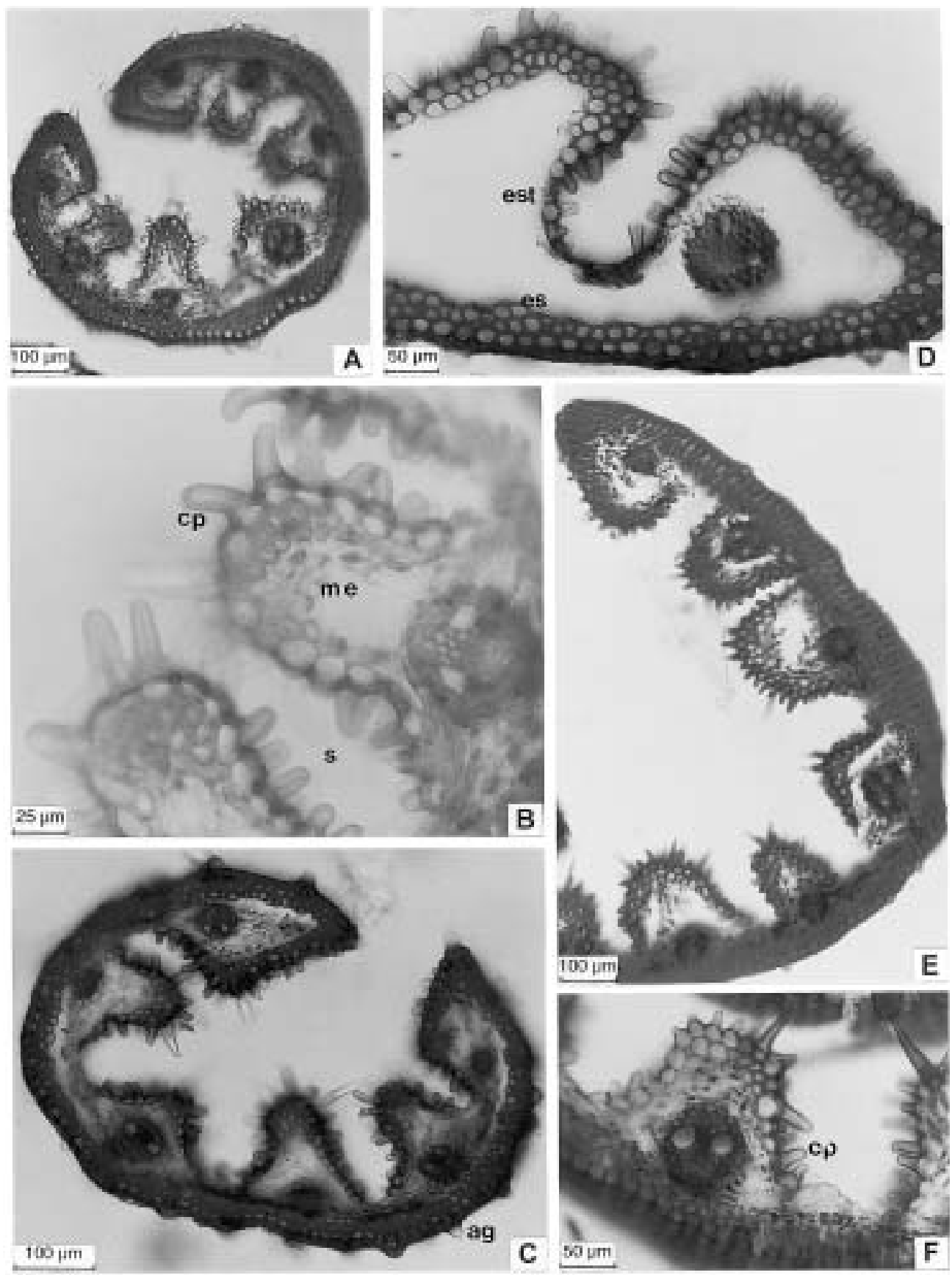

Figura 10. Deyeuxia eminens var. fulva (Griseb.) Rúgolo. Corte transversal de hoja. A-B. Material actual, A. Reve et D. Ramadori 141: A, corte transversal completo; B, detalle de A mostrando costilla y surcos. C-F. Material arqueológico: C-D, hojas en camada de gramíneas; $\mathrm{C}$, corte transversal completo, sitio PCz1, capa 2; D, detalle del corte transversal a nivel del margen, sitio PP4, capa 2; E-F. Nudo ( $\left.{ }^{\circ} 20\right)$, sitio PP11 B: E, parte del corte transversal de la lámina; F, detalle de $\mathrm{E}$ mostrando una costilla. Fotografías obtenidas con microscopio óptico (ag, aguijón; cp, célula papilosa; est, estoma; es, esclerénquima; me, mesófilo; s, surco).

Deyeuxia eminens var. fulva (Griseb.) Rúgolo. Transversal cut of a leaf. A-B. Current material, A. Reve et D. Ramadori 141: A, complete transversal cut; B, detail of A showing ribs and sulcus. C-F. Archaeological material: $C$-D, leaves in bed of grass strata; $C$, complete transversal cut, site PCz1, layer 2; D, detail of transversal cut at the margin level, site PP4, layer 2; E-F. knot ( $\left.N^{\circ} 20\right)$, site PP11 B: E, part of the transversal cut of the lamina; F, detail of E showing a rib. ag, thorn; cp, papilose cell; est, stoma; es, sclerenchyma; me, mesofilo; s, sulcus. The photographs were taken using an optical microscope. 

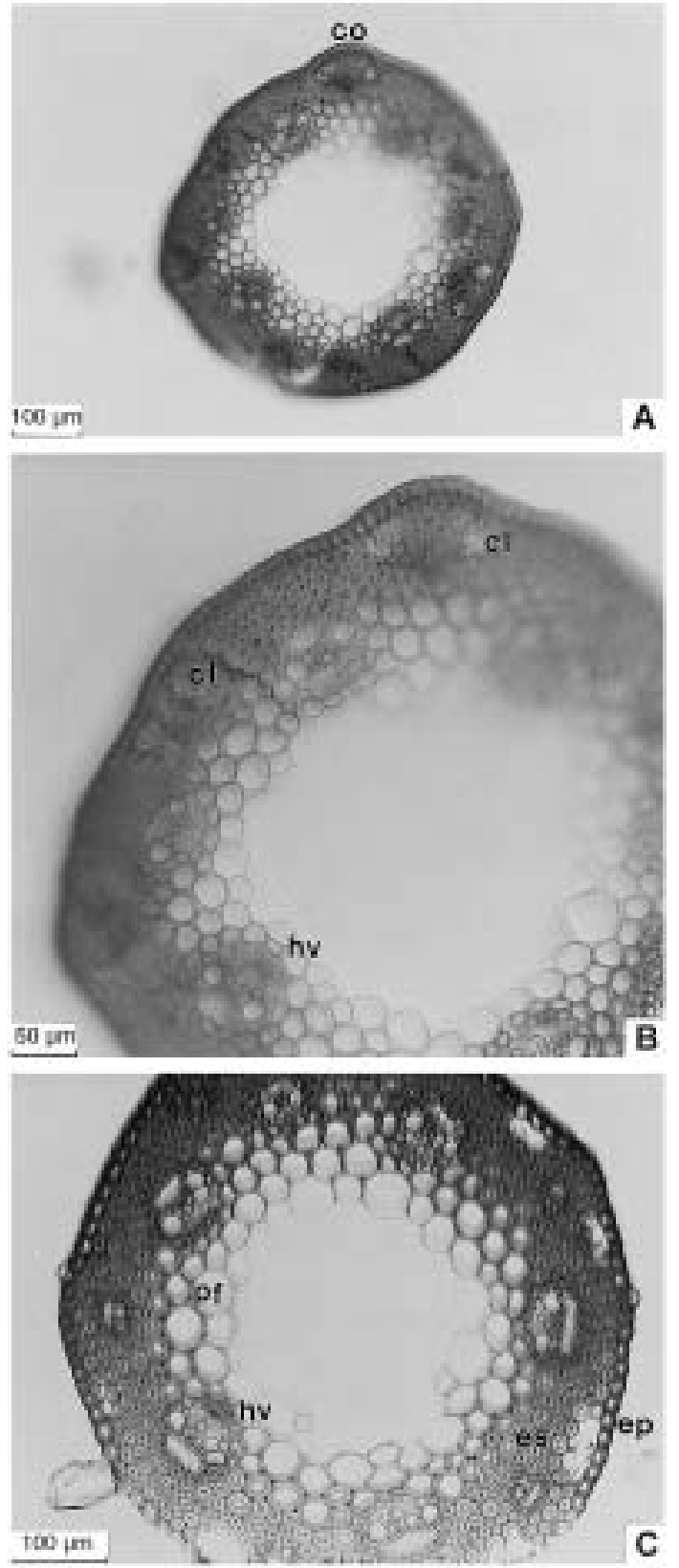

Figura 11. Deyeuxia eminens var. fulva. (Griseb.) Rúgolo. Corte transversal de caña florífera. A-B. Material actual, A. Reve et D. Ramadori 141: A, corte transversal completo; B, detalle de A. C. Material arqueológico, cordel ( $\left.\mathrm{N}^{\circ} 131\right)$, sitio PP9, estructura 2, sector III, tumba. Fotografías obtenidas con microscopio óptico (cl, clorénquima; co, costilla; ep, epidermis; es, esclerénquima; hv, haz vascular; pf, parénquima fundamental). Deyeuxia eminens var. fulva (Griseb.) Rúgolo. Transversal cut of flowering culms. A-B. Current material, A. Reve et D. Ramadori 141: A, complete transversal cut; $B$, detail of $A$. $C$. Archaeological material, cord $\left(N^{\circ} 131\right)$, site PP9, structure 2, area III, tomb. The photographs were taken using an optical microscope (cl, clorenchyma; co, rib; ep, epidermis; es, sclerenchyma; $h v$, vascular bundle; pf, essential parenchyma).
Pungentes Rúgolo, Stylagrostis (Mez) Rúgolo et Villavicencio y Chamaecalamus (Pilg.) Rúgolo et Villavicencio (Villavicencio 1995). Dichas especies presentan diferencias y semejanzas en la anatomía foliar y caulinar que se expresan en la Tabla 2 .

Existen pocos antecedentes bibliográficos previos que ilustren la anatomía foliar de las especies del género Deyeuxia. Villavicencio (1995) describe la epidermis y el transcorte foliar para los taxones presentes en Bolivia entre los cuales se incluyen los analizados en este trabajo. Si bien los caracteres de cada una de las entidades coinciden con lo observado, se han detectado algunas variaciones referidas a la distribución del esclerénquima, carácter que puede estar vinculado con las adaptaciones a diferentes condiciones ambientales. Por otra parte, al analizar el material arqueológico no es posible seleccionar el tipo y la posición de la hoja, por cuanto algunas diferencias estarían relacionadas con estos parámetros.

En cuanto a la procedencia de las especies recuperadas, la mayor parte fueron coleccionadas en un radio de $20 \mathrm{~km}$ a partir del sitio QS3; los restantes sitios se corresponden con distancias menores (Figura 1). Las especies más próximas son Deyeuxia curvula, $D$. deserticola y $D$. rigescens, correspondiendo la mayor distancia $(20 \mathrm{~km})$ a $D$. eminens var. eminens. La excepción es $D$. eminens var. fulva que no fue coleccionada en el área de estudio hasta el momento, de ahí que se considere el área de distribución -Laguna Blanca, Catamarca- a partir del material de Herbario. Por este motivo, se trata de una especie no local, lo cual implicaría una mayor movilidad de los grupos humanos que la utilizaron. Es importante aclarar que esta es una conclusión provisoria ya que es muy probable que $D$. eminens var. fulva se encuentre en el área de Antofagasta de la Sierra y pueda ser coleccionada en los próximos trabajos de campo.

Es interesante destacar que en la elaboración de artefactos, tales como cordeles, nudos y sogas, se utilizaron casi exclusivamente especies del género Deyeuxia (Figuras 4, 5 y 6 E). Lo mismo ocurre con las camadas que sirvieron como base de fardos funerarios en el nivel 2 de la capa $2 b$ de QS3 y en PP11-A, así como aquellas que fueron utilizadas a modo de "camas" en reparos rocosos 

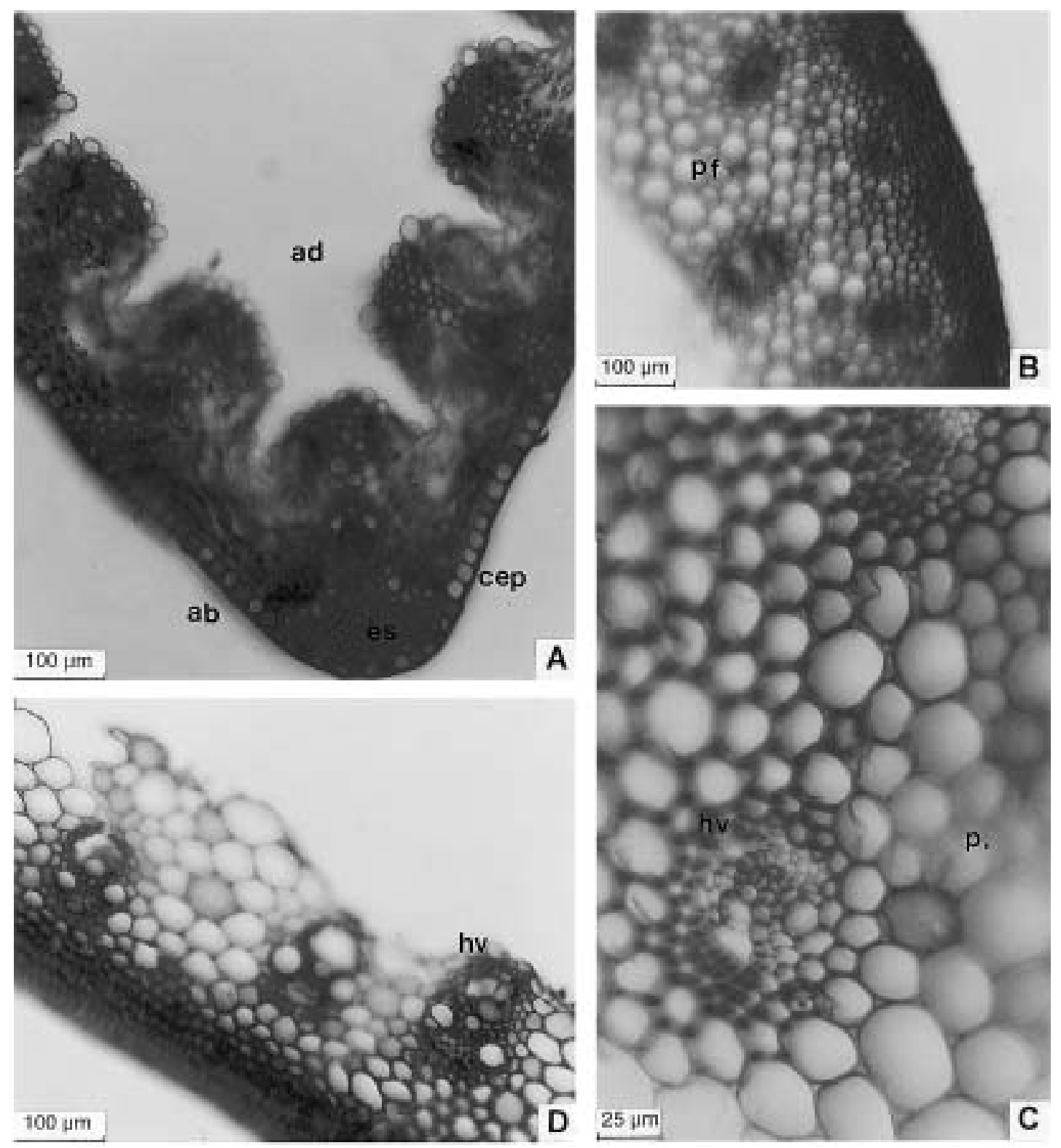

Figura 12. Deyeuxia rigescens (J. Presl) Türpe. A-C. Material actual, Rodríguez 10 y 27: A, parte del corte transversal de lámina; B-C, porción del corte transversal de caña florífera; C, detalle de B a nivel de haces vasculares. D. Material arqueológico, porción del corte transversal de caña florífera recuperada en camada de gramíneas, que acompaña al fardo funerario, sitio PP11-A. Fotografías obtenidas con microscopio óptico (ab, cara abaxial; ad, cara adaxial; cep, célula epidérmica; es, esclerénquima; hv, haz vascular; pf, parénquima fundamental).

Deyeuxia rigescens (J. Presl) Türpe. A-C. Current material, Rodríguez 10 y 27: A, detail of the lamina trasversal cut; B-C, part of transversal cut of the flowering culms; $C$, detail of $B$ at the level of vascular bundles. D. Archaeological material, part of the transversal cut of flowering culms recovered from a bed of grass strata of the funerary bundle, site PP11-A. The photographs were taken using an optical microscope (ab, abaxial face: ad, adaxial face; cep, epidermis cell; es, esclerénquima; $h v$, vascular haz; pf, fundamental parenchyma). 
tales como QS3 (nivel 12, capa 2b) y PP11-B. Las especies de Deyeuxia se destacan por su color dorado brillante y su textura suave (Rodríguez y Rúgolo de Agrasar 1999), lo cual constituye una característica morfológica importante en la confección de tecnofacturas y estructuras. Esto refleja una selección de materia prima a pesar de la disponibilidad de otras especies de gramíneas que habitan en el área de estudio y una asociación de algunas especies de Deyeuxia con rituales funerarios. Es importante aclarar que no existen datos paleoambientales que indiquen una mayor abundancia de especies de este género en la zona.

Por otra parte, si bien el género Deyeuxia predomina en las camadas que constituyeron pisos de ocupación en los sitios arqueológicos estudiados, su uso no es exclusivo. Otras especies, tales como Festuca weberbaueri Pilg., F. orthophylla Pilg., F. chrysophylla Phil., Puccinellia frigida (Phil.) I. M. Johnst., Jarava frigida (Phil.) F. Rojas y J. vaginata (Phil.) F. Rojas, también están representadas en dichos sitios. No obstante, un estudio estadístico realizado en el sitio QS3 demostró la mayor frecuencia de Deyeuxia eminens var. eminens en la capa 2 a y en los niveles $2 \mathrm{a} 12$ de la capa $2 \mathrm{~b}$, con respecto a las demás especies citadas (Rodríguez 1999).

En un análisis diacrónico se puede observar la aplicación de diferentes técnicas, algunas de ellas simples que se llevaron a cabo uniendo grupos de cañas y hojas de Deyeuxia eminens var. fulva, con una sola torsión (Figura 4 C-D); en otros casos los cordeles y sogas fueron confeccionados con dos cabos entrelazados de torsión independiente, utilizando las especies $D$. eminens var. eminens (Figura 4 A-B) y D. deserticola (Figura 5).

Es llamativo el hallazgo de haces de gramíneas -Deyeuxia eminens var. eminens - unidos con resinas y asociados con cordeles confeccionados utilizando haces vasculares foliares de palmera en un enterratorio (PP11-A) y en un sitio muy próximo (PP11-B), posiblemente asociado con el primero (Figura $6 \mathrm{~A}-\mathrm{B}$ ). Estos haces preparados formaron parte de la camada sobre la que se apoyaba el fardo funerario en PP11-A y de la "cama" que constituye el piso de ocupación en PP11-B.

Por lo tanto, estas conclusiones apoyan el uso preferencial del género Deyeuxia en el pasado prehistórico en la Puna Meridional Argentina, registrándose su presencia en los sitios arqueológicos estudiados en un rango temporal comprendido entre ca. $7410-460$ a.p.

Agradecimientos: Este trabajo fue financiado con los proyectos PIP-CONICET 4440 y 4975; PICT 1511 y 7531. Los autores agradecen al Dr. C. Baied por su colaboración para la obtención de material bibliográfico, al Lic. M. Belgrano por su asistencia fotográfica y a la Lic. A. Garbini y el Sr. V. Dudás por su colaboración en la diagramación de las figuras.

\section{Referencias Citadas}

Aschero, C. A.

1999 Investigaciones arqueológicas en Antofagasta de la Sierra. Campañas 1998. Informe presentado a la Dirección de Antropología de Catamarca. Manuscrito en posesión del autor.

Aschero, C.A., D. Elkin y E. Pintar

1991 Aprovechamiento de recursos faunísticos y producción lítica en el precerámico tardío. Un caso de estudio: Quebrada Seca 3 (Puna Meridional Argentina). Actas del XI Congreso Nacional de Arqueología Chilena Vol. 2:101-114. Santiago de Chile.

Aschero, C. A., L. Manzi y A. Gómez

1993-1994 Producción lítica y uso del espacio en el nivel 2 b4 de Quebrada Seca 3. Relaciones de la Sociedad Argentina de Antropología 19:191-214.

Cabrera, A. L.

1957 La vegetación de la Puna Argentina. Revista de Investigaciones Agrícolas 11 (1):317-413. Buenos Aires.

Cabrera, A. L.

1976 Regiones Fitogeográficas Argentinas. Enciclopedia Argentina de Agricultura y Jardinería. 2da edición. Tomo II. Editorial ACME.

Cabrera, A. L. y A. Willink

1980 Biogeografía de América Latina. Secretaría General de la Organización de los Estados Americanos. Serie de Biología. Monografía No 13, Washington D. C.

D'Ambrogio de Argüeso, A.

1986 Manual de Técnicas en Histología Vegetal. Editorial Hemisferio Sur S.A. Buenos Aires. Argentina.

Ellis, R. P.

1976 A procedure for standardizing comparative leaf anatomy in the Poaceae. I. The leaf-blade as view in transverse section. Bothalia 12:65-109.

Holmgren, P.K., N.H. Holmgren y L. C. Barnett

1990 Index Herbariorum, Part I. The Herbaria of the World ed 8, Reg. Veg. 120:1-693.

Martínez, J. G.

1998-1999 Ocupaciones humanas y tecnología de caza en Antofagasta de la Sierra (Catamarca) durante el Holoceno Temprano y Medio (ca. 10000-7000 AP). Informe de avance. Beca Interna de Formación de Postgrado CONICET. Manuscrito en posesión del autor. 
Metcalfe, C. R.

1960 Anatomy of Monocotyledons. 1. Gramineae. Clarendon Press, Oxford.

Rodríguez, M. F.

1997 Sistemas de asentamiento y movilidad durante el Arcaico. Análisis de macrovestigios vegetales en sitios arqueológicos de la Puna Meridional Argentina. Estudios Atacameños 14:43-60.

Rodríguez, M. F.

1999 Plant species (Families: Poaceae, Asteraceae, Fabaceae and Solanaceae) at an archaeological site of the Southern Argentine Puna. Journal of Ethnobiology 19 (2):229-247.

Rodríguez, M. F.

2000 Cambios en el uso de los recursos vegetales durante el Holoceno en la Puna meridional argentina. Actas del XV Congreso Nacional de Arqueología Chilena. En prensa.
Rodríguez, M. F. y Z. E. Rúgolo de Agrasar

1999 Deyeuxia eminens (Poaceae: Agrostideae) en un sitio arqueológico de la Puna Meridional Argentina (Provincia de Catamarca). Darwiniana 37 (3-4):229-242.

Rúgolo de Agrasar, Z. E.

1999 Las especies sudamericanas del género Deyeuxia (Poaceae, Agrostideae). Manuscrito en posesión de la autora.

Rúgolo de Agrasar, Z. E. y X. Villavicencio

1998 Deyeuxia (Gramineae): 181-235. 1998. En S. Renvoize Gramíneas de Bolivia. Royal Botanical Garden, Kew, England.

Villavicencio, $\mathrm{X}$.

1995 Revision der gattung Deyeuxia in Bolivien. Eine Taxonomisch Antomische Studie der in Bolivien Auftretanden Arten det gattunfg Deyeuxia. Dissertation zur Erlangung des grades eines Dokthors der Naturwissenschaften. Freien Universität, Berlin. 